\title{
The Combined Use of SEM-EDX, Raman, ATR-FTIR and Visible Reflectance Techniques for the Characterisation of Roman Wall Painting Fragments From Monte D'Oro Area (Rome): An Insight into Red, Yellow and Pink Shades.
}

Vittoria Guglielmi ( $\square$ vittoria.guglielmi@unimi.it )

Universita degli Studi di Milano

\section{Martina Andreoli}

University of Trento: Universita degli Studi di Trento

\section{Valeria Comite}

University of Milan: Universita degli Studi di Milano

\section{Anna Baroni}

University of Milan: Universita degli Studi di Milano

\section{Paola Fermo}

University of Milan: Universita degli Studi di Milano

\section{Research Article}

Keywords: Roman wall paintings, ATR- FTIR, Raman, SEM-EDX, visible reflectance, bone white, ash, gold.

Posted Date: April 19th, 2021

DOI: https://doi.org/10.21203/rs.3.rs-404608/v1

License: @ (i) This work is licensed under a Creative Commons Attribution 4.0 International License. Read Full License 


\section{Abstract}

The aim of this work has been the identification of the painter's materials employed in the wall's decoration of some destroyed building dating approximately between the first century B.C. and the first century A.D.

This research originates from a previously started joined archaeological and analytical investigation concerning a really varied group of findings that resulted from an excavation performed by Soprintendenza Archeologica in the area of Monte d'Oro in Rome. The focus of this study progression has been directed to a numerous selection of monochrome red, pink, and yellow pigmented fragments. The analyses were performed by means of scanning electron microscopy energy dispersive X-ray spectroscopy (SEM-EDX) combined to Raman and Fourier transform infrared (FTIR) spectroscopies; visible reflectance measurements have also been carried out in order to evaluate its appliance in such a kind of archaeological studies. Most attention has been given to the assessment of the performances of non-destructive techniques, precisely the ones achieved by portable Raman and visible reflectance instrumentation, above all to test their diagnostic capabilities. In addition to the expected and well-known pigments such as cinnabar, red ochre, hematite for the reds and yellow ochre for the yellows, the study highlighted a diffuse use of mixed colours and/or overlapped painted layers and confirmed in some cases the presence of gildings. Among the mixtures of pigments, the most singular outcome concerns the pink fragment revealing the possible application of bone white, which, based on of the known literature, seems to be rather uncommon as pigment in Roman wall decorations.

\section{Introduction}

For many years now, the field of archaeological and historical studies has been affected by the contribution of scientific research especially those carried out in chemical-physical characterisation of materials. In-depth knowledge of the characteristics of the materials used in the creation of works of art is certainly an added value in the field of their study, as it could be a further means towards understanding the works of art themselves, as well as their intrinsic value and the historical and social context to which they belonged.

In the case study presented in this paper, scientific investigations aspired to be a tool in identification of pigments and binders, also the organic ones if present, and hopefully of the painting techniques.

Despite of Vitruvius's and Pliny's advices for a long-lasting decoration through fresco technique (Vitr. De Arch., VII, 3, 6-7; Plin. Nat. Hist., XXXVI, 176), today it is known that Roman wall paintings present several combined execution features. Many studies have demonstrated that also organic binders and alkali sensitive pigments have been employed in Roman wall paintings, so the issue seems not trivial at all and the operating techniques of the artists as well as their technological expertise still remain of the main interest (Cuní 2012, 2016; Barbet 2000).

It is of major significance to mention that acquaintance of an artist's palette, as well as of the typology of other applied materials, is fundamental in several respects. The results might be a useful tool to outline information related for example to the availability of pigments in a specific geographical area, as well as of the raw materials used to prepare them, or the existence of particular trade routes for their supply (Siddall 2018). Furthermore, the study of the colour palette allows in part to shed light on commission and customer, especially concerning the use of certain very expensive pigments and other materials, which were accessible only to an upper class of Roman society.

It should be emphasised that knowledge of the materials and techniques employed in a work of art is also crucial in order to deal in the best possible way in view of any possible restoration or conservation works and could be also a tool for dating and even authenticate operas (Ruffolo et al., 2010; La Russa et al. 2014; Fermo \& Delnevo 2015; Bonizzoni et al. 2018). 
The subject of this study was a number of red, pink and yellow samples selected by archaeologists among 2442 fragments, collected in 2013 during a rescue excavation of the Soprintendenza Archeolgica in the Monte d'Oro area in Rome. This group of wall painting fragments was discovered in a private property during some building works, together with a significant amount of Roman pottery. The detailed study of the preserved painted motifs has allowed to ascribe some of them to Pompeian Third and Fourth style decorations, dating between the first century B.C. and the first century A.D. Unfortunately, no ancient building rests were detected in the discovery area and consequently the fragments are to consider contextless. Furthermore, there is no certainty that the whole amount of the wall painting fragments belonged to the same Roman building.

Analyses on these fragments were therefore performed also with the purpose to clarify some dubious aspects, as for example the belonging to a same room/building, or to a same period, verifying the correspondence of used pigments or techniques.

It must be stated that several samples from the same site have been previously analysed (Guglielmi et al. 2020 a,b) and that the present work exactly originates from the intriguing first results.

In this research a deeper study of the materials employed for the aforementioned fragment hues have been undertaken, since they had formerly presented the more interesting outcomes, as the presence of mixtures of pigments and/or overpainting and even the remains of some gilded decoration. The identification of that kind of materials is usually performed by the synergic employment of both elemental analyses and spectroscopic techniques (Bruni et al. 2008; Fermo et al. 2013;2020 Bonizzoni et al. 2016; Gargano at al. 2020; Tarquini et al. 2020). In this case, scanning electron microscopy equipped with an energy dispersive X-ray emission detector (SEM-EDX), Raman, attenuated total reflectanceFourier transform infrared (ATR-FTIR) and visible reflectance techniques have been applied.

SEM-EDX, Raman and visible reflectance analyses have been carried out on the samples as such: neither sampling nor coating was necessary. Only in the case of ATR-FTIR measurements micro samples of less than 1 square millimetre, literally grains of material have been taken from the painted surfaces.

It is also worth stating that Raman analyses have been performed by means of a benchtop micro-Raman spectrometer and a portable device; given that in both cases the analyses have been conducted in a totally non-destructive manner, in the context of the research a comparison between the results achievable by the two instruments has been attempted.

The final aim of this research was on the one hand the enlargement of scientific data about the archaeological discovery, through the study of more fragments, and on the other hand to test the performance of portable instrumentation. Indeed, both Raman and visible reflectance spectroscopies have been employed with the specific intention of estimate the significance of the results obtained with portable techniques in the perspective of further measurements to carry out on other polychrome fragments currently stored in Soprintendenza at Rome.

\section{Materials And Methods}

As previously explained, during the rescue excavation in 2013 a great number of contextless Roman wall painting fragments and pottery shards were recovered. After accurate cleaning solely by water or dry brushing, all kind of fragments were catalogued and studied by specialists. Concerning the wall paintings as subject of this research, they were grouped by the archaeologists on the basis of their "fondo"colours, iconography and preparation layers. Some preserved motifs, as already specified, pertain clearly to Pompeian Third and Fourth style decorations, although fragments are few and too small to reconstruct a whole wall painting scheme. Several monochrome pieces within the entire amount were finally sampled for chemical analyses, in order to achieve more information. 
The present research focuses essentially on every shade of the available red, pink, and yellow hues and precisely bright red, red (two fragments), pink, light red, yellow (two fragments), and violet. Beside the original inventory numbers, the pieces have been renamed by cardinal numbers as shown in Fig. 1 and Table 1.

Table 1

List of analysed wall painting samples

\begin{tabular}{|lll|}
\hline SAMPLE & Colour & Inventory number \\
\hline 1 & bright red/gold & 607354 \\
\hline 2 & red & 608046 \\
\hline 3 & bright red & 608043 \\
\hline 5 & pink & 608044 \\
\hline 6 & light red & n.inv. \\
\hline 7 & yellow & 608054 \\
\hline 8 & red & 608047 \\
\hline 11 & yellow & 608056 \\
\hline
\end{tabular}

The SEM-EDX measurements were carried out on all samples by means of a Hitachi TM-1000 scanning electron microscope equipped with an energy dispersive X-ray spectrometer (Oxford Instruments SwiftED).

In order to verify any possible significant morphological and chemical inhomogeneities among different points, firstly each sample has been largely observed by BSE detector. Then for each analysed fragment, depending on its size, a minimum of three up to nine BSE images and as many EDX analyses have been acquired on areas of approximately 10 square millilitres in size, moving the probe on different positions of the sample surface. Apart from samples 1, where gold particles have been detected as mentioned afterwards, the samples surface appeared pretty homogeneous.

The results of semi-quantitative SEM-EDX analyses are synthetically reported in Table 2, where each value represents the average percentage obtained for each element detected on samples. In any cases precision on the measurements was within $10 \%$. 
Table 2

SEM-EDX semi-quantitative analyses (wt\%). For each sample, depending on its size, the reported value per element has been obtained as the average of minimum three up to nine measurements on different areas

\begin{tabular}{|c|c|c|c|c|c|c|c|c|c|c|c|c|}
\hline Sample/Element & $\mathrm{Mg}$ & Al & Si & $S$ & $\mathrm{~K}$ & $\mathrm{Ca}$ & $\mathrm{Ti}$ & $\mathrm{Fe}$ & $\mathrm{Hg}$ & $\mathrm{Pb}$ & $\mathbf{P}$ & V \\
\hline 1 (bright red) & & 0.70 & 2.86 & 5.31 & 1.03 & 64.81 & & 0.59 & 24.71 & & & \\
\hline 2 (red) & & 1.30 & 4.10 & & 0.98 & 73.52 & & 13.28 & & 6.26 & & \\
\hline 3 (bright red) & & 1.03 & 3.63 & 7.68 & 0.45 & 48.25 & & 2.28 & 36.80 & & & \\
\hline 4 (pink) & & 0.92 & 3.74 & 2.20 & & 50.86 & & 1.36 & 10.76 & 26.90 & 2.22 & 0.78 \\
\hline 5 (light red) & 0.75 & 8.78 & 22.20 & & 4.10 & 46.53 & & 17.68 & & & & \\
\hline 6 (yellow) & & 4.21 & 11.71 & & 1.57 & 67.56 & & 14.61 & & & & \\
\hline 7 (red) & & 1.50 & 4.80 & & 0.53 & 77.77 & 0.60 & 14.80 & & & & \\
\hline 8 (yellow) & & 2.80 & 5.96 & & 0.58 & 72.52 & & 11.92 & & 6.22 & & \\
\hline 11 (violet) & & 0.20 & 3.87 & & & 71.97 & & 23.93 & & & & \\
\hline
\end{tabular}

Further analyses on samples 1 and 4, discussed in the following paragraphs, have been performed by a Hitachi TM4000 scanning electron microscope equipped with a 4-quadrant BSE detector, a low-vacuum SE detector and Oxford AztecOne EDX system. The latter have been basically employed to clarify the morphology of the gilded surface found on sample 1 and to verify the distribution of some elements on the extremely intriguing pink sample.

All the SEM-EDX analyses have been carried out on the samples as such at low vacuum condition and no coating application has been required (Cappelletti et al. 2005; Bruni et al. 2018).

For Raman analyses both by a BWTek i-Raman plus portable Raman spectrometer \& video microscope instrument, provided with a solid-state laser emitting at 785 as excitation source, a CCD array detector and a 50x objective and a BWTek i-Raman EX portable spectrometer equipped with a fibre optic probe of 85-micron diameter and a Nd-YAG laser emitting at $1064 \mathrm{~nm}$ have been employed. In both cases, Raman analyses have been carried out directly on the fragments without any sampling. Raman spectra have been achieved with $4 \mathrm{~cm}^{-1}$ resolution as the average of 20-40 scans and they have been acquired in the spectral range $100-2500 \mathrm{~cm}^{-1}$. Both spectrometers are provided with a convenient control that have permitted appropriate fine tuning of the laser power on the samples.

FTIR analyses have been performed by a Nicolet 380 spectrometer coupled with an ATR accessory Smart Orbit provided with a diamond crystal. The spectra have been acquired on micro-samples of about $1 \mathrm{~mm}^{2}$ investigating the spectral range $500-4000 \mathrm{~cm}^{-1}$ with a resolution of $4 \mathrm{~cm}^{-1}$. All spectra have been obtained as the result of 64 accumulations, with the exception of sample 1, that required 256 accumulations to achieve a satisfactory signal to noise ratio.

The identification of the substances has been achieved comparing FTIR and Raman spectra from samples to the ones available in our database or found in the literature.

Visible reflectance analyses have been performed by a Konica Minolta CM 2300d portable colorimeter. The instrument has been calibrated by means of its white $100 \%$ reflective reference and a $0 \%$ reflective zero calibration box. All measurements have been carried out on all the sample surfaces and repeated widespread on different areas of the same fragment up to ten times, depending on the size of the samples themselves. Reflectance spectra have been recorded between 400 and $700 \mathrm{~nm}$ and obtained as the average of three accumulations. 


\section{Results And Discussion}

In authors opinion a starting screening performed on all the fragments by SEM-EDX is generally a useful tool in order to have both a general idea on average morphological and elemental aspects about the samples and a sort of hint for the further instrumental analyses. In fact, it is well known that the presence of specific elements in many cases is enough for the identification of pigments and other possible components on the sample surface (Bruni et al. 2018; Comite et al. 2020).

The first SEM survey, performed by the Hitachi TM1000 instrument, thus with BSE detection, has revealed for each colour set of samples quite homogeneous surface layers, with the exception of sample 1 where some very intense bright small areas have been detected and then identified as gold by EDX analysis, as deeply discussed further on.

In all samples, fragment 1 included, the painted surface has shown a huge content in calcium (about 50-70\%) and quite high in silicon (up to about 22\%), and smaller uneven quantities of aluminium (1-2\%, with the exception of samples 5 where it is about $9 \%$ ), titanium (0.5\%) and potassium (about $1 \%$, with the exception of sample 5 where it is about $4 \%$ ), whose presence cannot be clearly correlated to any pigment; otherwise, it is likely that such signals originate from the plaster (Table 2). Actually, this was a first hint that the paintings were realised with a fresco technique (Piovesan et al. 2011; Crupi et al. 2015; Toschi et al. 2016). It must be underlined that also variable percentage of iron has been detected all over, but in this case, the phenomenon was partially ascribable to the presence of iron-based pigments as described further.

As regards the presence of elements that could be immediately related with specific pigments, the bight-red 1 and 3 samples and the pink one, have given the signals of mercury and sulphur, confirming the presence of cinnabar; violet, red, light-red, and yellow ones were characterised by the presence of iron, whose percentage were averagely higher respect to the other samples (Table 2). Taking into account also the hues of iron-rich fragments, the presence of iron has been attributed to red and yellow ochre and/or to other iron-based pigments such as hematite or goethite (Ergen et al. 2018; Guglielmi et al. 2020b).

In some samples, also a fair percentage of lead has been detected, whose presence is generally attributable to a sort of lead-based pigments such as for example lead white, minium, massicot etcetera (Paradisi et al. 2012; Fermo et al. 2013).

However, it is evident that SEM-EDX results did not complete the identification of components and the contribution of vibrational spectroscopies has been crucial for their characterisation.

It is worth noting that only the pink sample contains a certain percentage in phosphorous and vanadium. This result, that was unique among the whole group of fragments, is deeply discussed in the paragraph dedicated to pink hue.

Finally, in two cases, namely in samples 2 and 11, traces of barium have been detected, even not reported in Table 2. To be more precise, barium was nor extensively, neither homogeneously present on the samples surfaces but in both cases its identification has been associated with individual grains recognised as barium sulphate when investigated by punctual EDX analysis. For this reason and considering the context of the recovery as well, the presence of barium sulphate might be ascribed to contamination due to the burial environment.

The results of SEM-EDX analyses, clearly highlight the necessity to apply further analysis techniques to overcome the limitation associated to elemental analyses themselves.

In the following discussion the results of combined elemental, vibrational and visible reflectance techniques will be presented; for clearness they have been reported on the basis of the different hues. 
It is also to be early stressed that in all samples both FTIR and Raman measurements have revealed huge contents of calcite and silicates, otherwise any organic binder has been identified all over the painted layers; this leads more confidently toward the hypothesis that the pigments have been applied by a fresco technique.

\subsection{Red and light red}

The identification of red and light red pigments has been firstly attempted by means of non-invasive Raman spectroscopy. As previously mentioned, red samples are characterised by high iron content. Indeed, in their Raman spectra (Fig. 2) the bands attributable to red ochre have been recognised. To be more precise, Fig. 2a shows the spectrum obtained with the portable instrument on sample 7, where bands at 220,287, 404, $609 \mathrm{~cm}^{-1}$ are reported (Burgio \& Clark 2001; Froment et al. 2008; Di Lernia et al. 2016; Guglielmi et al. 2020b); Fig. 2b, that refers to the same sample, exhibits a quite similar spectrum, where only the bands at 220 and 404 are clearly distinguishable, probably because of the high fluorescence background; nevertheless, those bands appear sharper in that case.

The analyses have been repeated on several areas on red samples 2 and 7 and in all cases only the spectra of red ochre have been achieved, whereas no bands ascribable to any lead-based compound have been detected by means of Raman spectroscopy on sample 2. All spectra presented the unmistakable peak of calcite at $1086 \mathrm{~cm}^{-1}$ (Burgio \& Clark 2001).

In Fig. 2c and 2d Raman and micro-Raman spectra of light red sample 5 are shown; in this case the bands of calcite at 1085,711 and $282 \mathrm{~cm}^{-1}$ and the peaks at 463 and $207 \mathrm{~cm}^{-1}$ ascribable to quartz were the only detectable signals (Bikiaris et al. 2000; Di Lernia et al. 2016).

The spectrum shown in Fig. 2e, likewise any other spectrum achieved on light red sample, reports once more the bands of calcite and no traces of bands attributable to iron-based pigments have been recorded, perhaps because of both contribution of poorness of ochre signals in that sample and very high fluorescence background. It is to note that the spectrum in Fig. 2e also presented a particular broad band, whose maximum stands at about $780 \mathrm{~cm}^{-1}$. It is to early observe that the same band is present in spectrum $2 \mathrm{f}$ obtained on violet sample as discussed further on.

This feature, together with the already mentioned bands at 1085, 711 and $282 \mathrm{~cm}^{-1}$, has to be ascribed to the so-called limewash (Edwards et al. 2003), i.e. a lime-based preparation layer extensively used in Roman wall paintings (Piovesan et al. 2011; Crupi et al. 2015; Barone et al. 2016; Toschi et al. 2016).

Limewash particular Raman spectrum is essentially due to the presence of hydrated calcium oxide-hydroxide together with calcium carbonate (Schmid \& Dariz 2014) and it could have been originated from the bit surprising fact that the conversion of lime to calcium carbonate can be a really slow process (Edwards \& Farwell 2008).

In order to complete the characterisation of red samples, particularly on light red one, where no bands ascribable to any red pigment have been identified, ATR-FTIR spectra have been also recorded.

Figure 3 shows the ATR-FTIR spectra of red and light red samples, characterised by the strong bands of calcium carbonate at 1403-1430, 871 e $712 \mathrm{~cm}^{-1}$ (Andersen \& Brecevic 1991; Gulotta et al. 2013; Bruni et al. 2018) and by the bands around $1000 \mathrm{~cm}^{-1}$ as well as the ones at $912,520-530$ and $460-470 \mathrm{~cm}^{-1}$ due to the presence of silicate, clay minerals (possibly kaolinite) and iron oxides, i.e. the main components of red ochre (Helwig 1998; Burgio \& Clark 2001; Mortimore et al. 2004; Saikia \& Parthasarathy 2010; Chukanov 2014; Guglielmi et al. 2020b). Actually, only the signals at 535 and $470 \mathrm{~cm}^{-1}$ visible in spectrum of sample 2 might be clearly linked to iron oxide signals, because in most cases a superimposition by the very intense bands of clay minerals occurs, however that is quite common in red ochre FTIR spectra (Bikiaris et al. 2000; Di Lernia et al. 2016). 
Since the bands due to calcite have been found all over the analysed samples during this research, they are not going to be mentioned anymore in the following discussion, even though they have been always clearly indicated in the figures.

It is also to underline the presence of aragonite, particularly recognisable in sample 2 by the characteristic bands at 1082, 854 and $700 \mathrm{~cm}^{-1}$ (Fig. 3) (Mazzocchin et al.2006). It must be said that it was not the only case where aragonite has been detected by FTIR, otherwise its presence was quite ubiquitous in particular in pink sample, even not so evident as in just mentioned sample 2. It is also to remark that in all cases aragonite has been detected in association with calcite (Sbroscia et al. 2020; Amadori et al. 2015; Toschi et al. 2016).

As regards silicates, it has to be noted that the broad features at about 1000,525 and $460 \mathrm{~cm}^{-1}$ are quite stronger, besides than a bit different in shape, in light red sample in comparison to the red ones. Furthermore, also quartz, whose presence is proved both by the just mentioned broad band around $1000 \mathrm{~cm}^{-1}$ and especially by the characteristic bands at 798 and $778 \mathrm{~cm}^{-1}$ (Vaculíková \& Plevová 2005), indicated by a curly bracket in Fig. 3, seems to be contained in larger quantity in light red samples. Those outcomes are perfectly aligned with the previously presented results. In fact, it must be underlined that the percentage of silicon, aluminium and potassium in sample 5 was considerably higher compared to any other painted layer (Table 2). That appears compatible with the higher relative content in clays and quartz in FTIR spectra of light red sample, where the presence of the feature below $1000 \mathrm{~cm}^{-1}$ might be correlated with the presence of a potassium feldspar (Bosch-Reig et al. 2017). Therefore, it seems to be quite reasonable that the signal of quartz was so visible and extensively detected in Raman spectra of light red fragment as well as the fact that no iron oxide band has been detected. In accordance with those results, it can be stated that the variation of the red colour tone in red and light red samples is to be mostly attributed to different silicates and clay mixtures as regards both their relative percentage compared to iron oxide content and the typology of the mineral species in mixture (Bikiaris et al. 2000).

\subsection{Violet}

In Fig. 2 both Raman and micro-Raman spectra of sample 11 show the bands at 220, 289, 401 and $607 \mathrm{~cm}^{-1}$ ascribable to haematite (Burgio \& Clark 2001; Froment et al. 2008).

Similarly to what have been already discussed for light red sample 5, in one of the Raman spectra obtained with the portable device on violet sample, that is shown in Fig. $2 f$, there is the broad band attributable to limewash. In this case it is less noticeable, but still detectable, the peak at $711 \mathrm{~cm}^{-1}$ of calcite, probably due to a different percentage in the calcium carbonate/calcium hydroxide ratio on the indagated surface (Chiriu et al. 2014; Satish et al. 2000; Schmid \& Dariz 2014).

It must be evidenced here that those reported in Fig. 2 were not isolated cases; in fact, other similar Raman spectra have been recorded widespread on samples. Precisely, those particular features have been recorded when the portable instrument with the optical fibre have been used, since in this case the probe might have been accidentally directed to some more degraded parts of the painted surface.

It seems plausible that this peculiar pattern of the Raman spectra, due to the superimposition of not completely carbonated lime-based preparation layer and pigments signals, could be further evidence in support of the hypothesis that walls were painted using the fresco technique (Linn 2017).

In the case of violet sample, the pigment has been unequivocally identified as haematite by means of SEM-EDX and Raman techniques and it was not worth proceeding with micro-destructive FTIR analysis. 
The yellow samples demonstrate to be particularly characterised by high iron content. Raman analyses on sample 6 (Fig. 4a) achieved in all cases quite week spectra, characterised by intense fluorescence signals and where only calcite and the most intense band of goethite at $390 \mathrm{~cm}^{-1}$ have been detected (Froment et al. 2008). In Raman spectrum of sample 8 (Fig. 4b) the band of goethite appears even less intense, although discernible; that seem reasonable since sample 8 resulted less rich in iron. Furthermore, in all spectra obtained on sample 8 both with portable and micro-Raman spectrometers, a band at $143 \mathrm{~cm}^{-1}$ has been identified and assigned to the orthorhombic yellow form of PbO known as massicot (Smith \& Clark 2004, Coccato et al. 2021). This outcome accords with the naked eye observations which have evidenced a brighter hue in sample 8 , with elemental analyses performed on that sample and with the historical literature that reports a wide usage of lead-based substances by Romans also in paintings (Plin., Nat. Hist., XXXIV, 156-176 e XXXV, 30, 38, 49) (Rapp G.R. 2002).

Unfortunately, it was not possible to determine if the particular hue of sample 8 was due to a mix of yellow pigments, precisely yellow ochre and massicot, or to a superimposition of different yellow painting layers; in fact, that kind of information usually comes from the possibility to make polished sections and it was not the case.

In order to confirm the results of Raman investigation, ATR-FTIR spectra have been recorded. In Fig. 5, the spectra appear almost identical and perfectly in accordance with those reported in the literature for yellow ochre. In particular it is to point out the presence of main bands at 1110, 1032, 1009, 912, 534 and $468 \mathrm{~cm}^{-1}$ attributable to yellow ochre (Bikiaris et al. 2000; Di Lernia et al. 2016) alongside with the shoulder at about 1165 and the peaks at 798 and $778 \mathrm{~cm}^{-1}$ related to a small percentage of quartz (Vaculíková \& Plevová 2005) and indicated by a curly bracket in Fig. 5.

\subsection{Pink}

The pink sample has been immediately retained a separate case study because of the peculiar elemental composition characterised, among the elements extensively found on other fragments, by the presence of phosphorous and vanadium. Another distinctive trait was presence of high percentage of mercury and huge quantities of lead (Table 2).

Firstly SEM-EDX analyses were repeated with the Hitachi 4000 device in order to obtain EDX mapping and better verify the spatial distribution of elements on the surfaces, that have resulted homogeneously spread all over the pink surfaces (Fig. 6).

Then, the sample has been analysed by Raman spectroscopy, precisely with the portable instrument, especially due to the great size of sample 4, where the latter spectrometer has allowed to perform the necessary widespread Raman investigation in a reasonable time.

The obtained spectra (reported in Fig. 7 together with the spectra acquired on bright red samples 1 and 3) have shown the well-known bands of cinnabar at 253, 284 (sh) and $343 \mathrm{~cm}^{-1}$ (Aliatis et al. 2010; Bonizzoni et al. 2011). The band at $1085 \mathrm{~cm}^{-1}$ of calcite (not shown here) has also been detected all over the surfaces. It has been retained plausible in that case, more than in any other already discussed samples, that calcite has been employed as an extender, even if its presence seems perfectly in agreement with the use of a fresco technique as well; indeed, one statement does not exclude the other one.

These first results were quite surprising because it was supposed to find at the very least some lead-based substances. Then, in fact, the samples have been deeply investigated with the micro-Raman device too and this made it possible to recognise, besides cinnabar and calcite, also $\mathrm{PbO}$ in its tetragonal form known as litharge: the strong band at $147 \mathrm{~cm}^{-1}$, perhaps combined by the weaker broad feature at about $278 \mathrm{~cm}^{-1}$ (Fig. 8e), is attributable to litharge indeed (Burgio \& Clark 2001). 
Figure 8 shows some of the results of the analyses on sample 4, that have been obtained exploiting the peculiar spatial resolution of micro-Raman technique and performing the measurements on single grains. It should be also noted the dissimilar features achieved moving from one grain to another one over a small area of the sample, that reflects the different proportions in terms of composition of distinct analysed particles. It must also be stated that the signatures of litharge have been hardly ever detected on those samples; in fact, in most measurements only the bands of cinnabar and calcite have been detected and the spectra shown in Fig. 8 are the result of a really patient and accurate point by point investigation.

Combining SEM-EDX and Raman measurements outcomes, it appears realistic that cinnabar and litharge have been applied in two steps, precisely cinnabar over litharge (Clementi at al. 2011; Coccato et al. 2021).

It is certainly true that Raman bands of cinnabar are intrinsically really intense and therefore extremely visible even in the case of mixtures in which there is a prevalence of litharge, as suggested in this case by SEM-EDX results. However, cinnabar seems to have a sort of masking action, and this might be explained by assuming that the two substances were applied one on top of the other and that it was possible to detect litharge only in places where it emerges from the underlying layer, perhaps where the overpainting was not perfectly covering or in damaged areas. However, as previously stated, it was neither possible to make polished cross-sections nor to use a confocal-based technique, which could have been a possible alternative to verify that hypothesis. It is worth noting that Raman analyses has also allowed to exclude the existence of lead white pigment on pink samples.

All those outcomes had not even given reason of the presence of phosphorous and vanadium, since no Raman band attributable to related compounds has been found.

Therefore, ATR-FTIR analyses have been carried out and the results are shown in Fig. 9. In the FTIR spectra of pink sample a really particular feature has been observed, namely the presence of the two quite intense bands at 590 and 560 $\mathrm{cm}^{-1}$ attributable to calcium phosphates as apatite or hydroxyapatite (Berzina-Cimdina \& Borodajenko 2012; Grunenwald et al. 2014; Brangule \& Gross 2015; Tomasini et al. 2012). It must be stated that the presence of silicates, recognizable by the bands around $1000-1100 \mathrm{~cm}^{-1}$ and probably due to the plaster, have made the detection of phosphates more challenging since several important features of calcium phosphates themselves are hidden (BerzinaCimdina \& Borodajenko 2012).

It has also to be remarked that the presence of phosphates could have been possibly highlighted by Raman spectroscopy as well (Best et al. 2013; Cosano et al. 2016; Wang et al. 2017), but in this case no bands of phosphates have been identified. However, our case does not appear unique, since other studies of bone-based materials report similar outcomes, precisely the application of both FTIR and Raman spectroscopies to that kind of compounds where the evidence of phosphates derives only from FTIR spectrum (Lluveras-Tenorio et al. 2019).

Hydroxyapatite is the main component of bones, so this finding agrees to the presence of another white pigment, namely bone white, used as an extender together or in place of calcite. Bone white, whose chemical formula is $\mathrm{Ca}_{3}\left(\mathrm{PO}_{2}\right)_{2}$, is a greysh-white material that has been utilised since antiquity and it can be obtained by burning and calcination of animal bones at high temperature (Rapp G.R. 2002; Brooke et al. 2020).

According to published analyses, bone white as pigment seems not so common in Roman wall painting at Rome (Coccato et al. 2021). Nevertheless, at least at the Villa dei Quintili, not so far from Monte d'Oro area along the via Appia, bone white was detected in white samples of the first half of the second century A.D. (Crupi et al. 2015). As a matter of fact, the analysed pink sample from Monte d'Oro was already classified by the archeologists as something apart. The fragment presents indeed a different composition of its preparation layers, with small dark pozzolana inclusions. Also the painted surface layer with its polished aspect and the presence of gray veinings is unique among all catalogued 
rests. Results of the performed analyses confirm therefore substantially that this sample is to consider a unicum among the recovered wall paintings remains.

So far, the hypothesis, namely the use of bone white as an extender made intentionally to obtain the pink hue by mixing with the two red minerals cinnabar and litharge found in that piece, is not to rule out.

There is another intriguing conjecture about the presence of burnt bones that is not to exclude a priori: the combined discovery of litharge and bone residues leads to consider that it could be related to cupellatio, an antique metallurgic process really common in Roman times too (Plin. Nat. Hist. XXXIV, 47). It consists in a high temperature treatment of ores and alloys, that meant to separate noble metals, such as gold and silver, from other less precious metals.

In particular, silver does exist in nature especially in lead-based ores, so that its production as pure metal required cupellation of silver rich lead ores. The procedure was regularly carried out in presence of inert and porous materials and, among those, bones ash was commonly used (Nriagu 1985). Since the main residue of that kind of heating treatment was exactly litharge (Habashi F. 2016) and taking into account that bones ashes were regularly used during the process too, in authors opinion it seems plausible that those substances appear at the same time on this interesting pink sample.

Finally, it is worth underlining that only this pink sample has shown the presence, moreover contemporary to phosphorous, of vanadium too and that it was really intriguing to discover that it is not uncommon that exactly the latter element can be associated with bones (Barrio \& Etcheverry 2006).

\subsection{Bright-red}

All bright red samples, namely fragments coming from groups number 1 and 3 , were basically characterised by the presence of mercury and sulphur (Table 2). Raman analyses confirmed in all cases the presence of cinnabar ( $\mathrm{HgS})$, as shown in Fig. 7.

As already identified and reported by the archaeologists, routine SEM-EDX analyses confirmed the presence of gold in sample 1. Then sample 1 has been undergone to further SEM-EDX analyses. Figure 10 shows the detail of the gilded decoration observed by SE, BSE and EDX detectors.

The combined information derived from images and EDX maps allows to state that gold leaf has been applied, even if the extension of its surface is extremely small (Clementi et al. 2011; Barbet 2020).

Eventually, two micro-samples of fragment 1, precisely one from the gold leaf and the other from the red painted surface, have been collected from fragment 1 , since the presence of the residue of some organic binder wanted to be verified.

The spectrum obtained from the golden sample in Fig. 11b, has shown the presence of organic components, whose main features are the quite intense bands at about $3400 \mathrm{~cm}^{-1}$ ascribable to $\mathrm{O}-\mathrm{H}$ and/or $\mathrm{N}-\mathrm{H}$ stretching (Invernizzi et al. 2018) 2933, 2891 and $2863 \mathrm{~cm}^{-1}$ attributable to the $\mathrm{C}-\mathrm{H}$ stretching of $\mathrm{CH}_{3}$ and $\mathrm{CH}_{2}$ groups, the strong band at $1736 \mathrm{~cm}^{-}$

1 of a $\mathrm{C}=0$ bending in carboxylic esters and the band at $1223 \mathrm{~cm}^{-1}$ ascribable to $\mathrm{C}-\mathrm{O}$ stretching in carboxylic esters (Bruni \& Guglielmi 2014; Bonizzoni et al. 2011). Moreover, the spectrum also displays barely detectable features at 1669 and $1581 \mathrm{~cm}^{-1}$ respectively assigned to $\mathrm{C}=\mathrm{O}$ (amide I) and combination of $\mathrm{N}-\mathrm{H}$ bending and $\mathrm{C}-\mathrm{N}$ stretching bands (amide II) and at $3080 \mathrm{~cm}^{-1}$ identified as the first overtone of amide II band. Since bands around $2900 \mathrm{~cm}^{-1}$ are always present in organic compounds, the most diagnostic ones are the strong feature at $1736 \mathrm{~cm}^{-1}$ of carboxylic esters, possibly due to the presence of triglycerides, and all those assigned to amide, that are typical for proteinaceous eggbased binders (Amadori et al. 2015; Nodari \& Ricciardi 2019; Caggiani, et al., 2020). Also the acute shape of the band at 
about $3400 \mathrm{~cm}^{-1}$ is quite similar to the one of reported for $\mathrm{N}-\mathrm{H}$ stretching rather than the $\mathrm{O}-\mathrm{H}$ (Vahur et al. 2016; Nodari \& Ricciardi 2019).

Those considerations lead to think that the binder could have been realised with whole egg or egg yolk, because of the contemporary presence of fats (such as triglycerides and cholesterol) and proteins signals (Mills \&White 1999; Prinsloo et al. 2013).

However, the simultaneous existence of some oil or fat seems plausible, as well as perhaps some beeswax, since they respectively contain high quantities of triglycerides and long-chained esters (Mills \&White 1999; Duran et al., 2010).

This speculation is fundamentally based on the evidence that, as previously mentioned, the bands at about 2900,1736 and $1230 \mathrm{~cm}^{-1}$ are the main organic related bands in this spectrum and furthermore, the relative intensity of ester and amide bands seems not compatible with egg yolk alone (Mazzeo et al. 2008). Hence, it is likely that they are due to the contribution of more esters-containing substances. Moreover, it is to underline that the presence of the inorganic compounds signals probably hides some additional important features that otherwise might help in the challenging but not impossible identification of the binder by FTIR spectroscopy.

The possibly definitive identification of the organic substances present in sample 1 is going to be performed with GC-MS technique on the same micro-sample already analysed with FTIR and it will be part of a further work, specifically devoted to ancient organic binder characterisation.

Finally, it is worth noting that the comparison of the spectrum in Fig. 11b, with the spectrum obtained from the red surface (Fig. 11a) permits to better appreciate the differences between the two features, but especially allows to exclude that the signals of organic matter originate from the painting. This is to be considered further evidence that the "fondo" colours have been applied with a fresco technique and that the binder has been exclusively used for the application of the golden decoration.

\subsection{Visible reflectance analyses:}

As a final step in this work, visible reflectance analyses have been carried out on all samples, with the main aim of testing the diagnostic capabilities of our device. The colorimeter used for the measurements is in fact an instrument whose portability and user friendliness characteristics and especially non-destructiveness in relation to the artworks under investigation, make it a potentially useful tool in the field of pictorial analysis (Dal Fovo et al. 2020).

On the left side of Fig. 12 the spectra of a representing group of the analysed samples are shown, whereas on the right side their first derivatives have been reported; the latter have been calculated for a more precise reading of the points of flex of the original reflectance spectra.

What is immediately noticeable is the clear difference between the general trends in the spectra of iron-based pigments and cinnabar. The yellow specimen presents a pronounced slope at $550 \mathrm{~nm}$ and two absorbance bands at about 480 and $640 \mathrm{~nm}$, represented by minima in the spectrum. Light red, red and violet spectra show a very similar trend, where the main differences are in the placement of the more pronounced slope. To be more precise, light red sample shows a single slope at $578 \mathrm{~nm}$ and a slight absorbance around $480 \mathrm{~nm}$, whereas the other ones present two slopes, that stand at 588 and about $705 \mathrm{~nm}$ for red sample and at 594 and about $705 \mathrm{~nm}$ for violet.

The results obtained for yellow, red and violet samples perfectly accord to what has been reported in the literature for iron-based pigments such as yellow and red ochres and hematite (Aceto at al. 2014; Cheilakou et al. 2014). Otherwise, it is to underline that in the case of light red sample, the flex point is quite translated respect to red and violet ones; 
moreover, as previously mentioned a just barely but still detectable absorbance band at the same wavelength as the yellow sample has been detected.

It is well-known that the colour of ochres is related with grain size, but it has also been reported that the granulometry does not affect their reflectance curve trend (Elias et al. 2006; Dubiel et al. 2011).

Actually, it is reported in the literature that a shift toward lower wavelength of ochre could be related to different factors. On the one hand if a singular iron oxide is contained, the shift may be directly correlated to the percentage of white, whatever the white is (basically calcite, kaolinite and quartz in our case). It must be also said that the effect appears more pronounced in yellow ochres than in red ones (Elias et al. 2006; Gueli et al. 2018).

On the other hand, if two iron oxides such as hematite and goethite are contemporary present, obviously the colour, but also the wavelength corresponding to the point of flex moves, depending on the relative percentage of hematite and goethite (Elias et al. 2006).

In conclusion the shift toward lower wavelength in the light red sample might be related to the extremely poorness of the chromophore proved by the other performed analyses, but the presence of a certain percentage of goethite is not to be excluded.

The reflectance spectra of all samples from group 1, 3 and 4, i.e. the ones where cinnabar-based pigments have been detected, have shown the sigmoidal shape typical for semiconductor materials, characterised by a dramatic ascent at the inflexion point, in this case located at about $605 \mathrm{~nm}$ for bright red samples and a slightly below $600 \mathrm{~nm}$ for pink sample. Those outcomes correspond to those reported in the literature for cinnabar (Aceto at al. 2014; Gueli et al. 2018).

In Fig. 12 the first derivative maximum is positioned at 606 and $604 \mathrm{~nm}$ for respectively samples 1 and 3 and at $598 \mathrm{~nm}$ for pink sample 4; the dotted vertical lines have been added to better point out this variance, that instead was more evident in just discussed red ochres samples. An increasing blue shift of the point of flex of cinnabar when it is mixed with rising percentage of different white pigments, bone white included, is reported in the literature (Gueli et al. 2018), therefore it seems plausible that the observed slight difference between the curves of bright red and pink samples depend on the dilution of cinnabar in the latter.

\section{Conclusions}

In Table 3 an overview of the outcomes of this research is provided. 
Table 3

List of main elements, pigments and other compounds identified by means of combined SEM-EDX and spectroscopic techniques

\begin{tabular}{|c|c|c|c|c|c|}
\hline Sample & SEM-EDX & ATR-FTIR & Raman & $\begin{array}{l}\text { Visible } \\
\text { reflectance }\end{array}$ & Pigments \\
\hline 1 & $\begin{array}{l}\mathrm{Hg}+\mathrm{S}+ \\
\mathrm{Au}\end{array}$ & organic binder & cinnabar & cinnabar & $\begin{array}{l}\text { cinnabar + gold leaf + organic } \\
\text { binder }\end{array}$ \\
\hline 2 & $\mathrm{Fe}+\mathrm{Pb}$ & red ochre & red ochre & red ochre & red ochre \\
\hline 3 & $\mathrm{Hg}+\mathrm{S}$ & - & cinnabar & cinnabar & cinnabar \\
\hline 4 & $\begin{array}{l}\mathrm{Ca}+\mathrm{Hg}+ \\
\mathrm{Pb}+\mathrm{P}\end{array}$ & $\begin{array}{l}\text { calcite }+ \text { calcium } \\
\text { phosphate }\end{array}$ & $\begin{array}{l}\text { calcite + cinnabar } \\
\text { + litharge }\end{array}$ & cinnabar & $\begin{array}{l}\text { calcite }+ \text { cinnabar }+ \text { litharge }+ \\
\text { bone white/ash }\end{array}$ \\
\hline 5 & $\mathrm{Fe}$ & red ochre & quartz & $\begin{array}{l}\text { red + yellow } \\
\text { ochre }\end{array}$ & red + yellow ochre \\
\hline 6 & $\mathrm{Fe}$ & yellow ochre & yellow ochre & $\begin{array}{l}\text { yellow } \\
\text { ochre }\end{array}$ & yellow ochre \\
\hline 7 & $\mathrm{Fe}$ & red ochre & red ochre & red ochre & red ochre \\
\hline 8 & $\mathrm{Fe}+\mathrm{Pb}$ & yellow ochre & $\begin{array}{l}\text { yellow ochre + } \\
\text { massicot }\end{array}$ & $\begin{array}{l}\text { yellow } \\
\text { ochre }\end{array}$ & yellow ochre + massicot \\
\hline 11 & $\mathrm{Fe}$ & - & hematite & hematite & hematite \\
\hline
\end{tabular}

In this study a synergic use of elemental and spectroscopic techniques has been performed with the aim of identify both the pigments and the painting technique of the investigated wall painting fragments. It is to stress that, ATR-FTIR aside, all techniques have been successfully employed in a non-destructive way, namely without any sampling and this is of main importance in this field of the research.

In particular, the well-known good performance of Raman spectroscopy in pigments identification, has been once more evidenced and it is to stress that in almost all cases, the results derived from the benchtop device and the portable instrument were quite similar. However, it is also to be noted that in the particular case of pink sample only the microRaman instrument, because of its peculiar high spatial resolution, permitted a deeper insight of the pink colour layer, as also discussed further on.

Furthermore, visible reflectance measurements results were satisfying. In fact, on the one hand the identification of pigments achieved by means of reflectance spectra was compatible with the one obtained by the other employed techniques. On the other hand, the outcome of the light red sample and in a way of the pink sample too, are of the main interest in this case. In particular, it was quite surprising that only the study of reflectance spectrum gave an evidence of the possible presence of yellow ochre in light red sample, probably as an underlying layer below red ochre.

The defined colours palette reveals certainly some remarkable aspects. As mentioned at the beginning of this paper, the studied fragments are contextless and might belong to different buildings; this circumstance has never to be forgotten in regard to the interpretation of results. Nevertheless, it is interesting to note that among the selected samples, on the basis of their different visible hues to naked eye, some uncommon mixtures and/or pigments presence could be hypothesised.

Red hues, subdivided optically into bright reds (samples 1 and 3) and reds (samples 2 and 7), were, as expected, identified by analyses as cinnabar and red ochre. Cinnabar sample 1, with its small part of gold leaf is a very lucky archaeological discovery, considering the scarce number of such kind of findings. As supposed, the specific analysis in 
the gold application area confirmed the presence of an organic binder, probably prepared with egg and something else. The use of gildings on bright painting surfaces, usually on yellow motifs, might be reconsidered in this case, because of some barely detectable traces of a pattern, recognisable to the archaeologist's eye. First analytical research results had in fact signalled the presence of at least red ochre on this fragment. Further studies will solve this question.

Yellow hues, distinguished in two samples (samples 6 and 8) on the basis of different intensities of their colour, have been outlined even by analyses as different. Beyond yellow ochre identified as unique pigment in sample 6, the lead compound pigment massicot was also detected in sample 8. This observation inspires the idea, that we are dealing with a pigment mixture to obtain a specific yellow hue.

Outcomes concerning light red sample 5, with its particularly worn surface, highlighted a probable stratification of yellow and red painting layers, whereby the latter could have been applied through lime as inorganic binder. Archaeologists had already observed that the fragment has a spotted-like yellow and red surface, originating probably from the consumption of overlapped painting layers.

The most surprising results concern, however, the pink sample 4. In fact, the discovery of such an uncommon material combination, presenting cinnabar, calcite, the lead compound litharge and bone white/ash is really satisfying in terms of Roman wall painting knowledge increase. Worth to note also that pink colour itself is rather rare in paintings. According to literature-based pigment descriptions, the few documented pink samples do not resemble chemically to the Monte d'Oro's one. Usually, red iron oxide-based pigments or cinnabar are mixed with white pigments as aragonite, calcite or dolomite to create the pink hue. This time something new seems to have been outlined, i.e. the abundant presence of bone with/ash all over the sample surface. Documented few times used as white pigment at Rome, in sample 4 the bone ash has quite surely to be considered as an intentional adding, even in presence of calcite as whitening pigment. Indeed, bone white has a greyish aspect, and, as initially observed by archaeologists this mixture has given this particular shade of pink with greyish veining. If this mixture was skilfully prepared to reproduce for example a faux marble panel remains an intriguing hypothesis.

Considering the archaeological importance of this findings and the significance of the results achieved by means of our non-destructive portable instrumentation, it is in the authors perspectives to go further with an analytical survey to be performed in situ.

\section{Declarations}

\section{Ethics approval and consent to participate: Not applicable.}

Consent for publication: Not applicable.

Availability of data and materials: The datasets used and/or analysed during the current study are available from the corresponding author on reasonable request.

Competing interests: The authors declare that they have no competing interests.

Funding: Not specific funding were received.

Author Contributions: Conceptualisation: [Vittoria Guglielmi, Paola Fermo and Martina Andreoli], Methodology: [Vittoria Guglielmi, Paola Fermo and Valeria Comite], Formal analysis and investigation: [Vittoria Guglielmi, Anna Baroni and Valeria Comite], Data curation: [Vittoria Guglielmi], Visualisation: [Vittoria Guglielmi], Writing-original draft: [Vittoria Guglielmi], Writing-review and editing: [Vittoria Guglielmi, Paola Fermo, Martina Andreoli and Valeria Comite], Supervision: [Vittoria Guglielmi and Paola Fermo]. 
Acknowledgements: The authors kindly acknowledge Dr. Massimo Tagliaferro and Nanovision S.r.l. (Italy) for the scientific support and for having provided us with the Hitachi TM-4000 instrument, Dr. Daniel Barchewitz (B\&W Tek) and Dr. Andrea Cipolla (Metrohm Italiana) for their scientific support and for having provided us with the Raman instrumentation and Dr. Sergio Mineo, archaeologist of the Parco Archeologico dell'Appia Antica and editor of the forthcoming volume "Antichità di Monte d'Oro," for the permission to study these fragments and to publish the results.

\section{References}

1. Aceto M, Agostino A, Fenoglio G, Idone A, Gulmini M, Picollo M, Ricciardi P, Delaneyf JK (2014) Characterisation of colourants on illuminated manuscripts by portable fibre optic UV-visible-NIR reflectance spectrophotometry. Anal Methods 6:488-1500 DOI: 10.1039/C3AY41904E

2. Aliatis I, Bersani D, Campani E, Casoli A, Lottici PP, Mantovana S, Marino IG (2010) Pigments used in Roman wall paintingsin the Vesuvian area. J. Raman Spectrosc. 41(11):1537-1542 DOI: 10.1002/jrs.2701

3. Amadori ML, Barcelli S, Poldi G, Ferrucci F, Andreotti A, Baraldi P, Colombini MP (2015) Invasive and non-invasive analyses for knowledge and conservation of Roman wall paintings of the Villa of the Papyri in Herculaneum, Microchem J 118:183-192, DOI: https://doi.org/10.1016/j.microc.2014.08.016

4. Andersen FA \& Brecevic L (1991) Infrared spectra of amorphous and crystalline calcium carbonate. Acta Chem. Scand. 45:1018-1024. DOI: 10.1002/chin.199209005

5. Barbet A (2000) La pittura romana: dal pictor al restauratore / Alix Barbet, con la collaborazione di Claudine Allag, edizione italiana a cura di Gianni Ciurletti e Daniela Scagliarini Corlàita. In: (ed) University Press, Bologna, Imola pp 12-15.

6. Barone G, Bersani D, Coccato A, Lauwers D, Mazzoleni P, Raneri S, Vandenabeele P, Manzini D (2017) Nondestructive Raman investigation on wall paintings at Sala Vaccarini in Catania (Sicily). Appl Phys A 122:838 DOI: 10.1007/9783-662-55417-3_2 6

7. Barrio DA \& Etcheverry SB (2006) Vanadium and bone development: putative signaling pathways. Can J Physiol Pharmacol 84(7):677-86. DOI: 10.1139/y06-022.

8. Berzina-Cimdina L \& Borodajenko N (2012) Research of Calcium Phosphates Using Fourier Transform Infrared Spectroscopy. SourcelnTech. Infrared Spectroscopy - Materials Science, Engineering and Technology

9. Best SP, Clark RJR, Daniels MAM, Porter CA, Withnall R (2013) Identification by Raman microscopy and visible reflectance spectroscopy of pigments on an Icelandic manuscript. Stud Conserv 40(1):31-40

DOI:https://doi.org/10.1179/sic.1995.40.1.31

10. Bikiaris D, Daniilia S, Sotiropoulou S, Katsimbiri O, Pavlidou E, Moutsatsou AP, Chryssoulakis Y (2000) Ochre-di erentiation through micro-Raman and micro-FTIR spectroscopies: Application on wall paintings at Meteora and Mount Athos, Greece. Spectrochim Acta A Mol Biomol Spectrosc 2000, 56A(1):3-18 DOI: 10.1016/s13861425(99)00134-1.

11. Bonizzoni L, Bruni S, Guglielmi V, Milazzo M, Neri O (2011) Field and laboratory multi-technique analysis of pigments and organic painting media from an Egyptian coffin (26th dynasty). Archaeometry 2011, 53(6): 12121230.53 DOI: 10.1111/j.1475-4754.2011. 00592.x

12. Bonizzoni L, Bruni S, Galli A, Gargano M, Guglielmi V, Ludwig N, Lodi L, Martini M (2016) Non-invasive in situ analytical techniques working in synergy: The application on graduals held in the Certosa di Pavia. J. 126:172-180 DOI: 10.1016/j.microc.2015.12.001

13. Bonizzoni L, Bruni S, Gargano M., GuglielmiV, Zano C, Pezzotta A, Pilato A, Auricchio T, Delvaux L, Ludwig N (2018) Use of integrated non-invasive analyses for pigment characterisation and indirect dating of old restorations on one Egyptian con of the XXI dynasty. Microchem. J 138:122-131 DOI: https://doi.org/10.1016/j.microc.2018.01.002 
14. Bosch-Reig F, Gimeno-Adelantado JV, Bosch-Mossi F, Doménech-Carbó A (2017) Quantification of minerals from ATR-FTIR spectra with spectral interferences using the MRC method. Spectrochim Acta A Mol Biomol Spectrosc 181:7-12 DOI: 10.1016/j.saa.2017.02.012

15. Burgio L \& Clark RJH (2001) Library of FT-Raman spectra of pigments, minerals, pigment media and varnishes, and supplement to existing library of Raman spectra of pigments with visible excitation. Spectrochim Acta A 57(7):1491521 DOI: 10.1016/S1386-1425(00)00495-9

16. Brangule A \& Gross K (2015) Importance of FTIR Spectra Deconvolution for the Analysis of Amorphous Calcium Phosphates. Mater Sci Eng 77(1):1-6 DOI: 10.1088/1757-899X/77/1/012027

17. Brooke C, Edwards H, Vandenabeele P, Lycke S, Pepper M (2020) Raman Spectroscopic Analysis of an Early 20th Century English Painted Organ Case by Temple Moore. Heritage 3(4):1148-1161, DOI: https://doi.org/10.3390/heritage3040064

18. Bruni S, Caglio S, Guglielmi V, Poldi G (2008) The joined use of n.i. spectroscopic analyses - FTIR, Raman, visible reflectance spectrometry and EDXRF - To study drawings and illuminated manuscripts. Applied Physics A 92(1):103108 DOI: $10.1007 /$ s00339-008-4454-x

19. Bruni S, Guglielmi V, Della Foglia E, Castoldi M, Bagnasco Gianni G (2018) A non-destructive spectroscopic study of the decoration of archaeological pottery: from matt-painted bichrome ceramic sherds (southern Italy, VIII-VII B.C.) to an intact Etruscan cinerary urn. Spectrochim Acta A Mol Biomol Spectrosc 191:88-97 DOI: 10.1016/j.saa.2017.10.010

20. Bruni S \& Guglielmi (2014) Identification of archaeological triterpenic resins by the non-separative techniques FTIR and 13C NMR: The case of Pistacia resin (mastic) in comparison with frankincense. Spectrochim Acta A Mol Biomol Spectrosc SPECTROCHIM ACTA A 121C:613-622 Follow journal DOI: 10.1016/j.saa.2013.10.098

21. Caggiani C., Coccato A, Mazzoleni P, D’Alessio A, Russo A, Barone G (2020) Integrated analytical approach to unveil the secrets of the recently discovered "Sphinx Room": a new piece of Domus Aurea puzzle. Herit Sci 8:124. DOI: https://doi.org/10.1186/s40494-020-00465-1

22. Cappelletti G, Ardizzone S, Fermo P, Giardini S (2005) The influence of iron content on the promotion of the zircon structure and the optical properties of pink coral pigments. J Eur Ceram 25(6):911-917 DOI:

10.1016/j.jeurceramsoc.2004.04.023

23. Cheilakou E, Troullinos M, Koui M (2014) Identification of pigments on Byzantine wall paintings from Crete (14 ${ }^{\text {th }}$ century AD) using non-invasive Fiber Optics Di

use Reflectance Spectroscopy (FORS). J Archaeol Sci 41:541-555 DOI: 10.1016/j.jas.2013.09.020

24. Chiriu D, Ricci PC, Polcaro A, Braconi P, Lanzi D, Nadali D (2014) Raman Study on Pompeii Potteries: The Role of Calcium Hydroxide on the Surface Treatment. J. Spectrosc. 435026:1-10 DOI:

http://dx.doi.org/10.1155/2014/435026

25. Chukanov NV (2014) Infrared Spectra of Mineral Species, In: Springer Geochemistry/Mineralogy 3rd edn. Springer, Berlino, Germany, pp. 14-1726.

26. Clementi C, Ciocan V, Vagnini M, Doherty B, Tabasso ML, Conti C, Brunetti BG, Miliani C (2011) Non-invasive and micro-destructive investigation of the Domus Aurea wall painting decorations. Anal Bioanal Chem 401:1815-1826 DOI: 10.1007/s00216-011-5250-6

27. Coccato A, Mazzoleni P, Spinola G, Barone G (2021) Two centuries of painted plasters from the Lateran suburban villa (Rome): investigating supply routes and manufacturing of pigments. J Cult Herit 48:171-185 DOI: $10.3390 / \min 11010004$

28. Comite V, Andreoli M, Atzei D, Barca D, Fantauzzi M, La Russa MF, Rossi A, Guglielmi V, Fermo P (2020) Degradation products on Byzantine glasses from Northern Tunisia. Appl Sci10(21):7523 DOI: 10.3390/app10217523

Page $17 / 29$ 
29. Cosano D, Mateos LD, Jiménez-Sanchidrián C, Rafael Ruiz J (2016) Identification by Raman microspectroscopy of pigments in seated statues found in the Torreparedones Roman archaeological site (Baena, Spain). J 130: 191-197 DOI: 10.1016/j.microc.2016.09.003

30. Crupi V, Galli G, La Russa MF, Longo F, Maisano G, Majolino D, Malagodi M, Pezzino A, Ricca M, Rossi B, Ruffolo SA, Venuti V (2015) Multi-technique investigation of Roman decorated plasters from Villa dei Quintili (Rome, Italy) Appl Surf Sci 349:924-930 DOI: 10.1016/j.apsusc.2015.05.074

31. Cuní J (2012) Characterization of the binding medium used in Roman encaustic paintings on wall and wood. Methods 4(3):659-669 DOI: 10.1039/C2AY05635F

32. Cuní, J (2016) What do we know of Roman wall painting technique? Potential confounding factors in ancient paint media analysis. Herit Sci 4, 44 DOI: 10.1186/s40494-016-0111-4

33. Dal Fovo A, Mazzinghi A, Omarini S, Pampaloni E, Ruberto C, Striova J, Fontana R (2020) Non-invasive mapping methods for pigments analysis of Roman mural paintings. J Cult Herit 43:311-318, DOI: https://doi.org/10.1016/j.culher.2019.12.002

34. Di Lernia S, Bruni S, Cislaghi I, Cremaschi M, Gallinaro, M, Gugliemi V, Mercuri AM, Poggi G, Zerboni A (2016) Colour in context. Pigments and other coloured residues from the Early-Middle Holocene site of Takarkori (SW Libya). Archaeol Anthropol Sci 8:381-402 DOI: 10.1007/s12520-015-0229-4

35. Dubiel SM, Cieslak J, Tarasiuk J, Niziol J (2010) Relationship between Colours of Ochre from Roussillon and Content of Iron-Bearing Minerals. Appl Clay Sci 51(1-2):54-60 DOI:https://doi.org/10.1016/j.clay.2010.11.001

36. Duran A, Jimenez De Haro MC, Perez-Rodriguez JL, Franquelo ML, Herrera LK, Justo (2010) A Determination of pigments and binders in Pompeian wall paintings using synchrotron radiation - high-resolution x-ray powder diffraction and conventional spectroscopy - chromatography. Archaeometry 52(2):286-307 DOI: https://doi.org/10.1111/j.1475-4754.2009.00478.x

37. Edwards HGM, Middleton PS, Jorge Villar SE, de Fariac DLA (2003) Romano-British wall-paintings II: Raman spectroscopic analysis of two villa sites at Nether Heyford, Northants. Anal Chim Acta 48(2):211-221DOI: 10.1016/S0003-2670(03)00333-7

38. Edwards HGM \& Farwell DW (2008) The conservational heritage of wall paintings and buildings: an FT-Raman spectroscopic study of prehistoric, Roman, mediaeval and Renaissance lime substrates and mortars. J Raman Spectrosc 39(8):985 - 992 DOI: 10.1002/jrs.1917

39. Elias M, Chartier C, Prevot G, Garay H, Vignaud C (2006) The colour of ochres explained by their composition. Mater Sci Eng B 127:70-80 DOI: 10.1016/j.mseb.2005.09.061

40. Ergen D, La Russa MF, Ruffolo SA, Fort R, Sánchez Montes AL (2018) Characterization of the wall paintings in La Casa de los Grifos of Roman city Complutum. Eur Phys J Plus 133(9):1-13 DOI: 10.1140/epjp/i2018-12223-7

41. Fermo P, Piazzalunga A, De Vos M, Andreoli M (2013) A multi-analytical approach for the study of the pigments used in the wall paintings from a building complex on the Caelian Hill (Rome). Appl Phys A Mater 113(4):11091119 DOI: 10.1007/s00339-013-7754-8

42. Fermo P, Delnevo E (2015) Analisi e caratterizzazione dei pigmenti dei dipinti murali dei secoli I-IV d.C. In Caelius II. Pars Inferior. In: Englen A, Filetici MG, Palazzo P, Pavolini C, Santolini R., (ed) Le Case Romane sotto la Basilica dei Ss. Giovanni e Paolo, L'Erma di Bretschneider, Roma, Italy, pp. 466, 468, 471, 473, 479.

43. Fermo P, Mearini A, Bonomi R, Arrighetti E, Comite V (2020) An integrated analytical approach for the characterization of repainted wooden statues dated to the fifteenth century. Microchem. J. 157:105072.

44. Froment F, Tournié A, Colomban P (2008) Raman identification of natural red to yellow pigments: Ochre and ironcontaining ores. J. Raman Spectrosc 39(5):560 - 568 DOI: 10.1002/jrs.1858 
45. Gargano M, Bonizzoni L, Grifoni E, Melada J, Guglielmi V, Bruni S, Ludwig N. (2020) Multi-analytical investigation of panel, pigments and varnish of The Martyirdom of St. Catherine by Gaudenzio Ferrari (16th century). J. Cult. Herit. 46:289-297 DOI: 10.1016/j.culher.2020.06.014

46. Gueli A, Gallo S, Pasquale S (2018) Optical and colorimetric characterization on binary mixtures prepared with coloured and white historical pigments. Dyes Pigm 157:342-350 DOI: 10.1016/j.dyepig.2018.04.068

47. Guglielmi V, Fermo P, Andreoli M, Comite V (2020a) A multi-analytical survey for the identification of the red and yellow pigments of coloured sherds discovered in the Monte d'Oro area (Rome). Proceedings 2020 IMEKO TC-4 International Conference on Metrology for Archaeology and Cultural Heritage, pp. 548-553 ISBN: 978-92-990084-9-2

48. Guglielmi V, Comite V, Andreoli M, Dematin F, Lombardi CA, Fermo P (2020b) Pigments on Roman Wall Painting and Stucco Fragments from the Monte d'Oro Area (Rome): A Multi-Technique Approach. Appl Sci 10(20),7121: 1-18. DOI: https://doi.org/10.3390/app10207121

49. Gulotta D, Bertoldi M, Bortolotto S, Fermo P, Piazzalunga A, Toniolo L (2013) The Angera stone: Achallenging conservation issue in the polluted environment of Milan (Italy). Environ. Earth Sci. 2013, 69:1085-1094 DOI: $10.1007 / \mathrm{s} 12665-012-2165-2$

50. Grunenwald A, Keyser C, Sautereau AM, Crubézy E, Ludes B, Drouet C (2014) Revisiting carbonate quantification in apatite (bio)minerals: a validated FTIR methodology. J Archaeol Sci 49:134-141 DOI:

https://doi.org/10.1016/j.jas.2014.05.004

51. Habashi F.(2016) Pigments through the Ages. Inter Ceram 65(4):156-165 DOI: 10.1007/BF03401164

52. Helwig K (1998) The Characterization of Iron Earth Pigments Using IR Spectroscopy, in Postprints of IRUG2. In: Pretzel B edn., Victoria \& Albert Museum (V\&A), London, UK, pp. 83-91.

53. Invernizzi C, Rovetta T, Licchelli M, Malagodi M (2018) Mid and Near-Infrared Reflection Spectral Database of Natural Organic Materials in the Cultural Heritage Field. Int. J Anal Chem. 2018:1-16 DOI: 10.1155/2018/7823248

54. La Russa MF, Belfiore CM, Comite V, Barca D, Bonazza A, Ruffolo SA, Crisci GM, Pezzino A (2014) A scientific approach to the characterisation of the painting technique of an author: the case of Raffaele Rinaldi. Appl Phys $A$ 114(3):733-740 DOI: 10.1007/s00339-013-7866-1-

55. Linn R (2017) Layered pigments and painting technology of the Roman wall paintings of Caesarea Maritima Author links open overlay panel. J Archaeol Sci Rep 11:774-781 DOI: https://doi.org/10.1016/j.jasrep.2016.12.018

56. Lluveras-Tenorio A, Spepi A, Pieraccioni M, Legnaioli S, Lorenzetti G, Palleschi V, Vendrell M, Colombini MP, Tinè MR, Duce C, Bonaduce I (2019) A multi-analytical characterization of artists' carbon-based black pigments J. Therm Anal Calorim 138:3287-3299

57. Mortimore JL, Marshall LJR, Almond MJ, Hollins P, Matthews W (2004) Analysis of Red and Yellow Ochre Samples from Clearwell Caves and Catalhoyuk by Vibrational Spectroscopy and Other Techniques. Spectrochim Acta A Mol Biomol Spectrosc 60(5):1179-88 DOI: 10.1016/j.saa.2003.08.002

58. Mazzeo R, Prati S, Quaranta M, Joseph E, Kendix E, Galeotti M (2008) Attenuated total reflection micro FTIR characterisation of pigment-binder interaction in reconstructed paint films. Anal. Bioanal. Chem 392:65-76 DOI: 10.1007/s00216-008-2126-5

59. Mazzocchin GA, Orsega EF, Baraldi P, Zannini P (2006) Aragonite in Roman Wall Paintings of the VIlla Regio, Aemilia, and Xa Regio, Venetia Et Histria. Annali di Chimica, Società Chimica Italiana 96(7-8):377-387 DOI: https://doi.org/10.1002/adic.200690040

60. Mills J \&White R (1999) Organic Chemistry of Museum Objects. Taylor \& Francis Ltd

61. Nodari L \& Ricciardi P (2019) Non-invasive identification of paint binders in illuminated manuscripts by ER-FTIR spectroscopy: a systematic study of the influence of different pigments on the binders' characteristic spectral features. Herit. Sci. 7:7 DOI: 10.1186/s40494-019-0249-y 
62. Nriagu NJ (1985) Cupellation: The oldest quantitative chemical process. J Chem Educ 62(8):668-674 DOI: https://doi.org/10.1021/ed062p668

63. Paradisi A, Sodo A, Artioli D, Botti A, Cavezzali D, Giovagnoli A, Polidoro C, Ricci MA (2012) Domus aurea, the 'Sala delle Maschere': chemical and spectroscopic investigations on the fresco paintings. Archaeometry 4(6):1060-1075 DOI: https://doi.org/10.1111/j.1475-4754.2012.00678.x

64. Piovesan R, Siddall R, Mazzoli C, Nodari L (2011) The Temple of Venus (Pompeii): a study of the pigments and painting techniques. J. Archaeol Sci 38(10):2633-2643 DOI: 10.1016/j.jas.2011.05.021

65. Prinsloo LC, Tournié A, Colomban P, Paris C, Bassetta ST (2013) In search of the optimum Raman/IR signatures of potential ingredients used in San/Bushman rock art paint. J Archaeol 40(7):2981-2990 DOI: 10.1016/j.jas.2013.02.010

66. Ruffolo SA, La Russa MF, Barca D, Casoli A, Comite V, Nava G, Crisci GM, De Francesco AM, Miriello D (2010) Mineralogical, petrographic and chemical analyses for the study of the canvas "Cristo alla Colonna" from Cosenza, Italy: a case study. Period di Mineral 79:71-79 DOI: 10.2451/2010PM0022

67. Saikia BJ \& Parthasarathy G (2010) Fourier transform infrared spectroscopic characterization of kaolinite from Assam and Meghalaya, Northeastern India. J Mod Phys 1(1):206 DOI: 10.4236/jmp.2010.14031

68. Satish IK, Rajappan V, Sooryakant GH, Arumugamangalam VR, Debojit C, Samiran M (2000) Insights into the formation of hydroxyl ions in calcium carbonate: temperature dependent FTIR and molecular modelling studies. J Mater Chem 10(8):1835-1840 DOI: 10.1039/B001837F.

69. Schmid T \& Dariz P (2014) Shedding light onto the spectra of lime: Raman and luminescence bands of CaO, $\mathrm{Ca}(\mathrm{OH})_{2}$ and $\mathrm{CaCO}_{3}$. Raman Spectrosc 46(1):141-146 DOI: 10.1002/jrs.4622

70. Sbroscia M, Cestelli-Guidi M, Colao F, Falzone S, Gioia C, Gioia P, Marconif C, Mirabil Gattia D, Loreti EM, Marinelli M, Missori M, Persia F, Pronti L, Romani M, Sodo A, Verona-Rinati G, Riccia MA, Fantoni R (2020) Multi-analytical nondestructive investigation of pictorial apparatuses of “Villa della Piscina” in Rome. Microchem J 153:104450 DOI: https://doi.org/10.1016/j.microc.2019.104450

71. Siddall R (2018) Mineral pigments in archaeology: Their analysis and the range of available materials. Minerals 8(5),201:1-35 DOI:10.3390/min8050201.

72. Smith GD, Clark RJH (2004) Raman microscopy in archaeological science. Archaeol. Sci., 31:1137-1160 DOI: 10.1016/j.jas.2004.02.008

73. Rapp GR (2002) Archaeomineralogy (Natural Science in Archaeology Series) In: Springer, Berlin Heidelberg New York, pp 213 DOI 10.1007/978-3-540-78594-1

74. Tarquini O, Pronti L, Lorenzetti EG, Felici AC (2020) Pigment identification on campana reliefs from the palatine hill and colosseum valley in Rome. J Cult Herit 43:294-302.

75. Tomasini E., Siracusano G., Maier M.S.(2012) Spectroscopic, morphological and chemical characterization of historic pigments based on carbon. Paths for the identification of an artistic pigment. Microchemical Journal 102:28-37 https://doi.org/10.1016/j.microc.2011.11.005.

76. Toschi F, Colosi F, Lentini A, Paladini A (2016) A multidisciplinary study of Roman painted plasters from Roman villa in Ponti Novi (Sabina area, Lazio, Italy). J Archaeol Sci Rep 7:114-122 DOI: 10.1016/j.jasrep.2016.04.002

77. Paradisi A, Sodo A, Artioli D, Botti A, Cavezzali D, Giovagnoli A, Polidoro C, Ricci MA (2012) Domus aurea, the 'Sala delle Maschere': chemical and spectroscopic investigations on the fresco paintings. Archaeometry 4(6):1060-1075 DOI: https://doi.org/10.1111/j.1475-4754.2012.00678.x

78. Vaculíková L \& Plevová E (2005) Identification of clay minerals and micas in sedimentary rocks. Acta Geodyn Geomater 2(2):167-175 
79. Vahur S, Teearu A, Peets P, Joosu L, Leito I (2016) ATR-FT-IR spectral collection of conservation materials in the extended region of 4000-80 cm-1. Anal Bioanal Chem 408:3373-3379 DOI: 10.1007/s00216-016-9411-5

80. Wang M, Qian R, Bao M, Zhu P (2017) Raman, FT-IR and XRD study of bovine bone mineral and carbonated apatites with different carbonate levels. Mater Lett 210: 203-206 DOI: 10.1016/j.matlet.2017.09.023

\section{Figures}
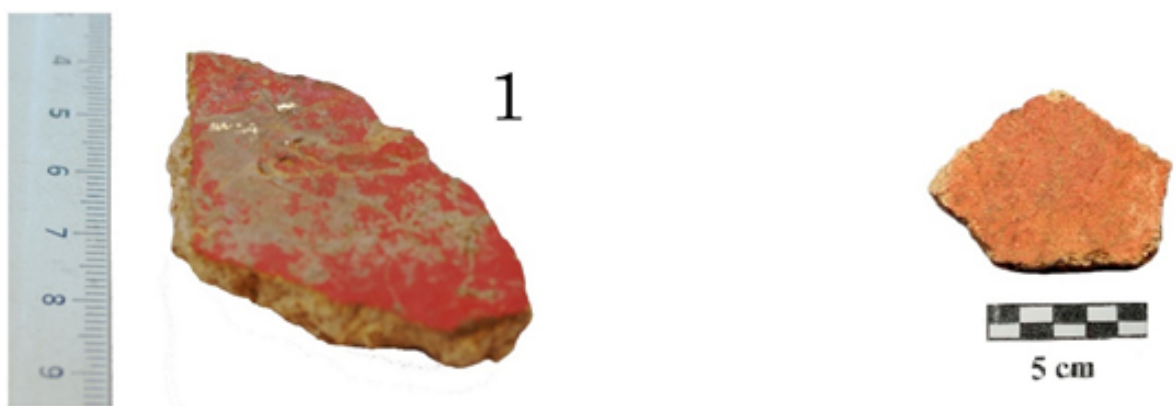

5
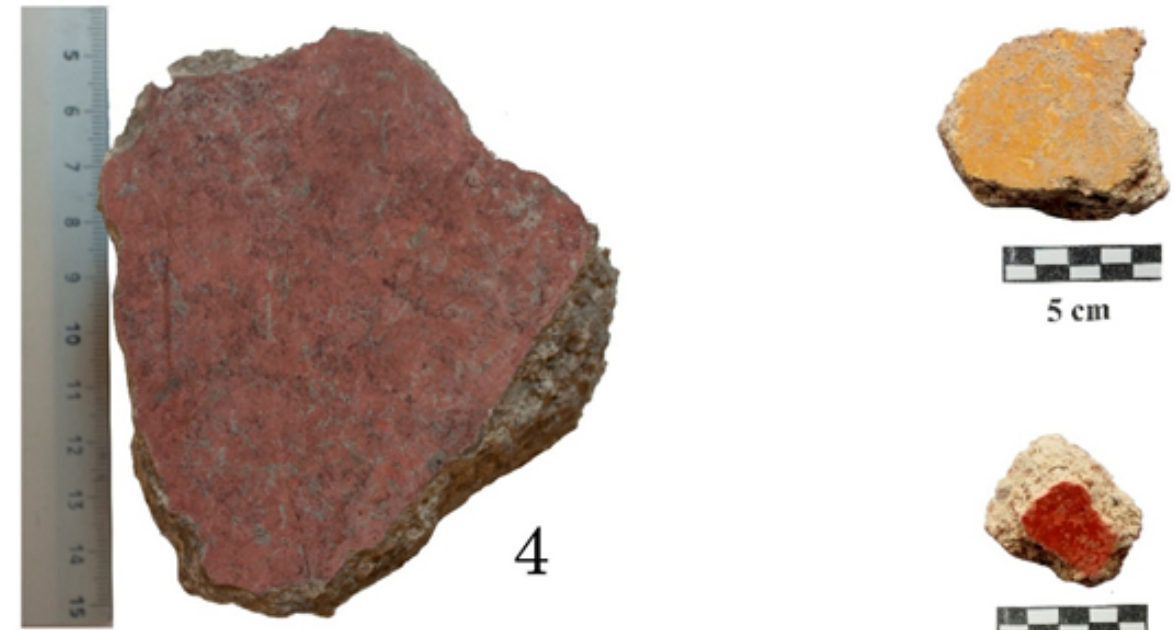

6

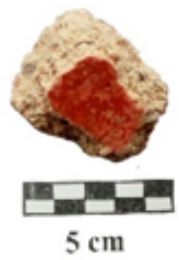

7

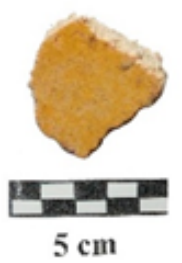

8

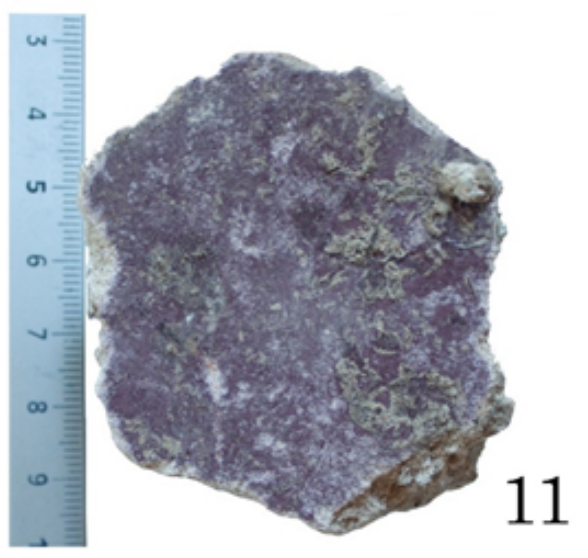

\section{Figure 1}

Some of Monte d'Oro's analysed samples: 1. Bright red with gilding (n.inv. 607354); 4. Pink (n.inv. 608044), 5. Light red (n. inv.), 6. Yellow (n.inv. 608054), 7. Red (n.inv. 608047), 8. Yellow (n.inv. 608056), 11. Violet (n.inv. 608042) 


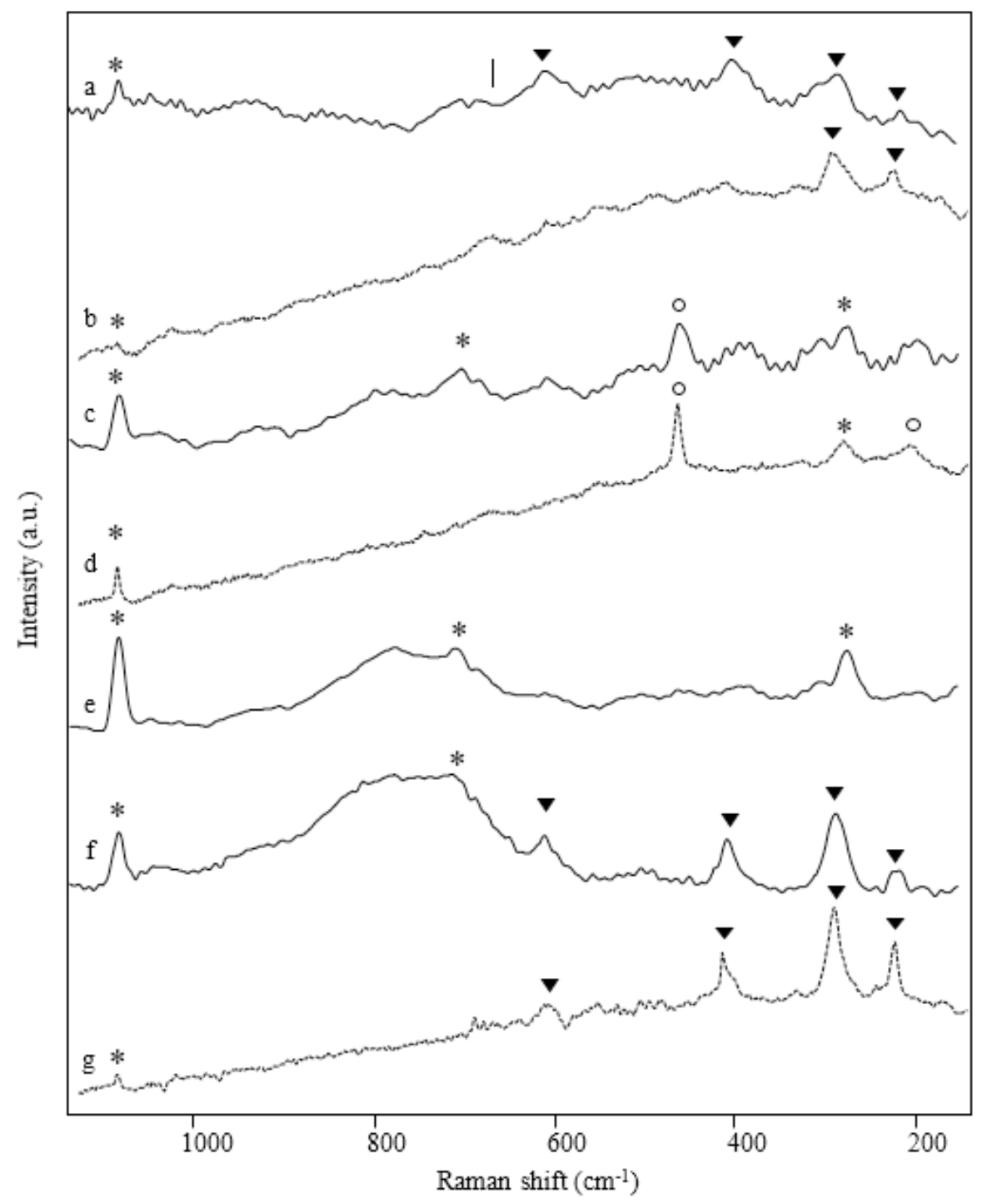

Figure 2

Raman spectra acquired by a portable Raman spectrometer with $1064 \mathrm{~nm}$ excitation (solid line) and by a micro-Raman spectrometer with $785 \mathrm{~nm}$ excitation (dotted line) on samples: a) red 7, b) red 7, c) light red 5, d) light red 5, e) light red 5, f) violet 11 and g) violet 11 . Triangles indicate ochre/hematite peaks, asterisks indicate calcite and circles quartz peaks 


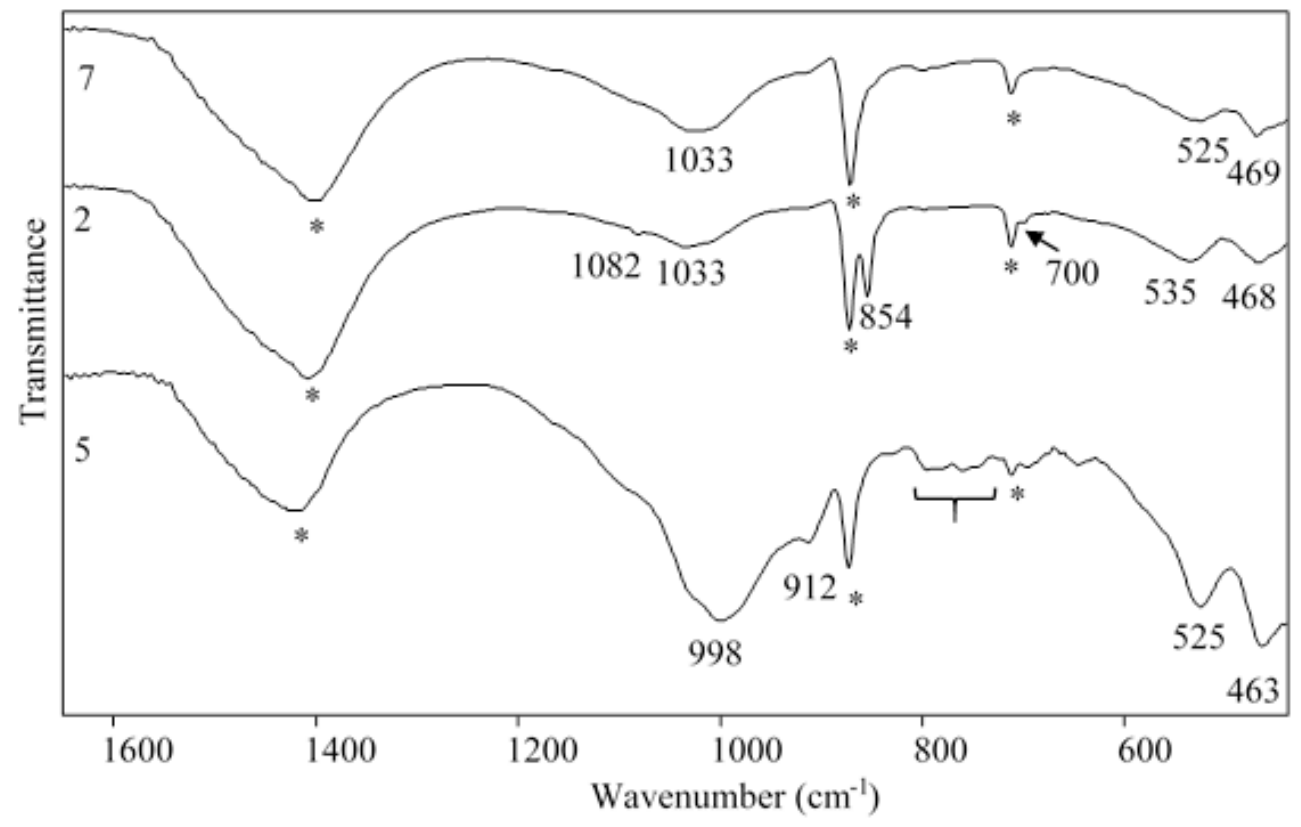

\section{Figure 3}

ATR-FTIR spectra of red 2, 7 and light red 5 samples; the peaks of calcite are marked with an asterisk, some quartz bands are indicated by a curly bracket

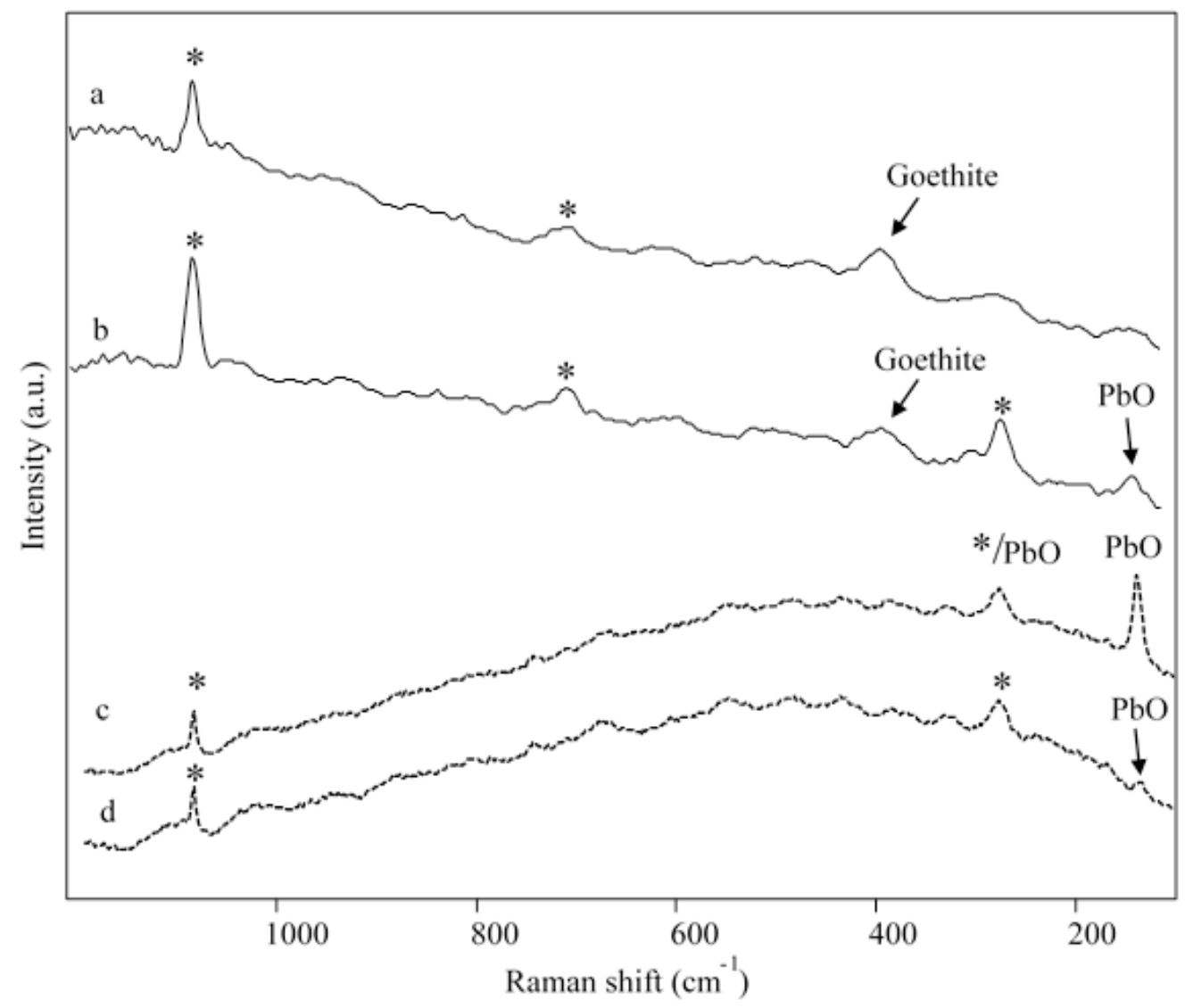




\section{Figure 4}

Raman spectra acquired by a portable Raman spectrometer with $1064 \mathrm{~nm}$ excitation (solid line) and by a micro-Raman spectrometer with $785 \mathrm{~nm}$ excitation (dotted line) on samples: a) yellow 6, b) yellow 8, c) and d) single different yellow grains on sample 8 . Asterisks indicate peaks of calcite.

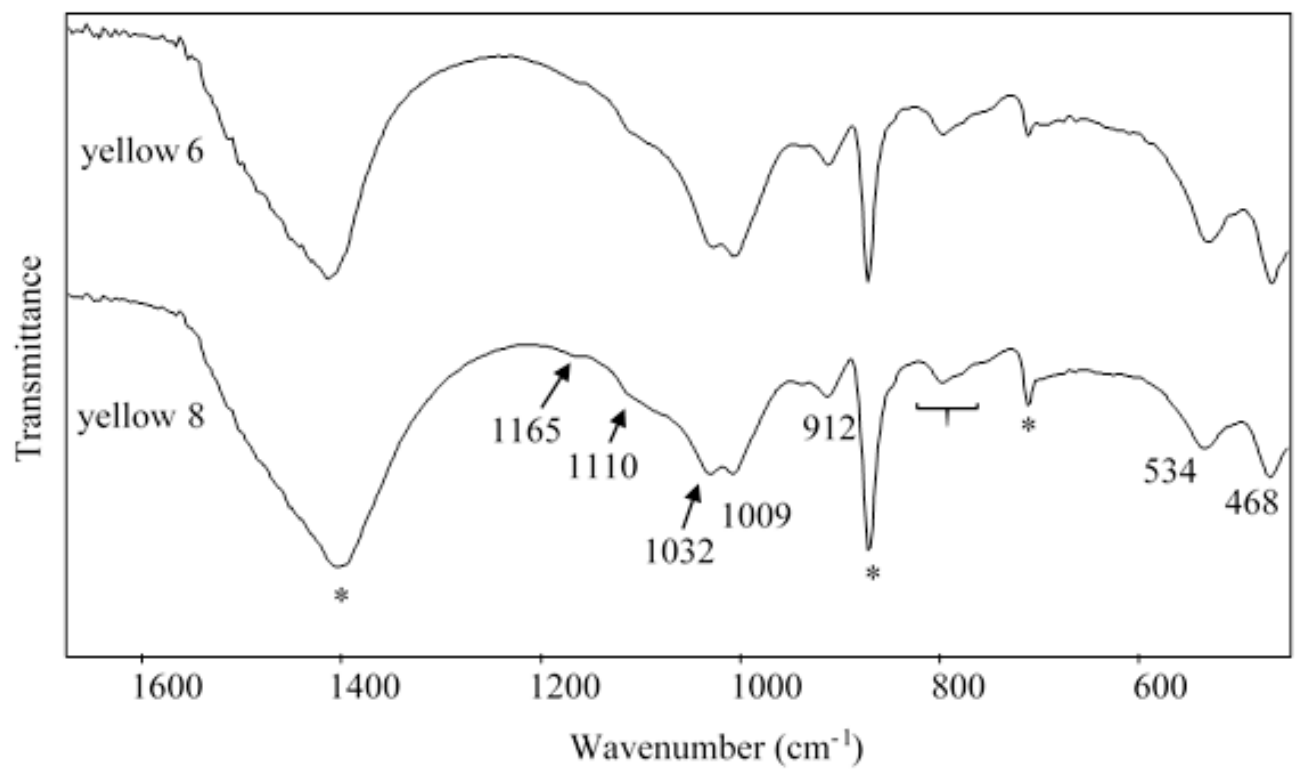

Figure 5

ATR-FTIR spectra of yellow samples 6 and 8 . Peaks due to calcite are indicated with an asterisk. Some quartz bands are indicated by a curly bracket
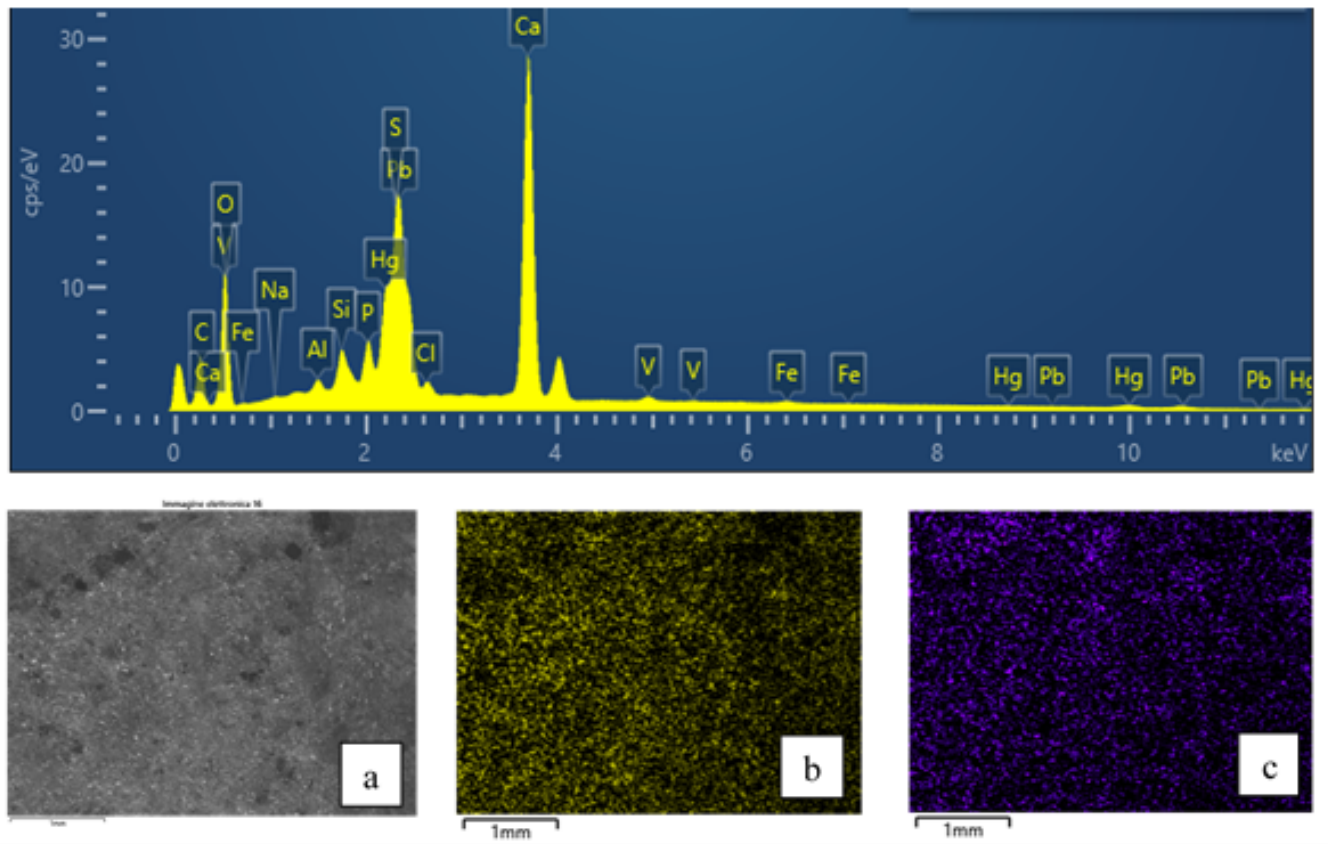

Figure 6 
SEM-EDX analysis on sample 4: on top the whole EDX spectrum obtained from the area of about $12 \mathrm{~mm} 2$ corresponding to BSE image in $a$; in $b$ and $c$ the distribution of respectively phosphorous ( $K$ series) and vanadium ( $K$ series) on the same area

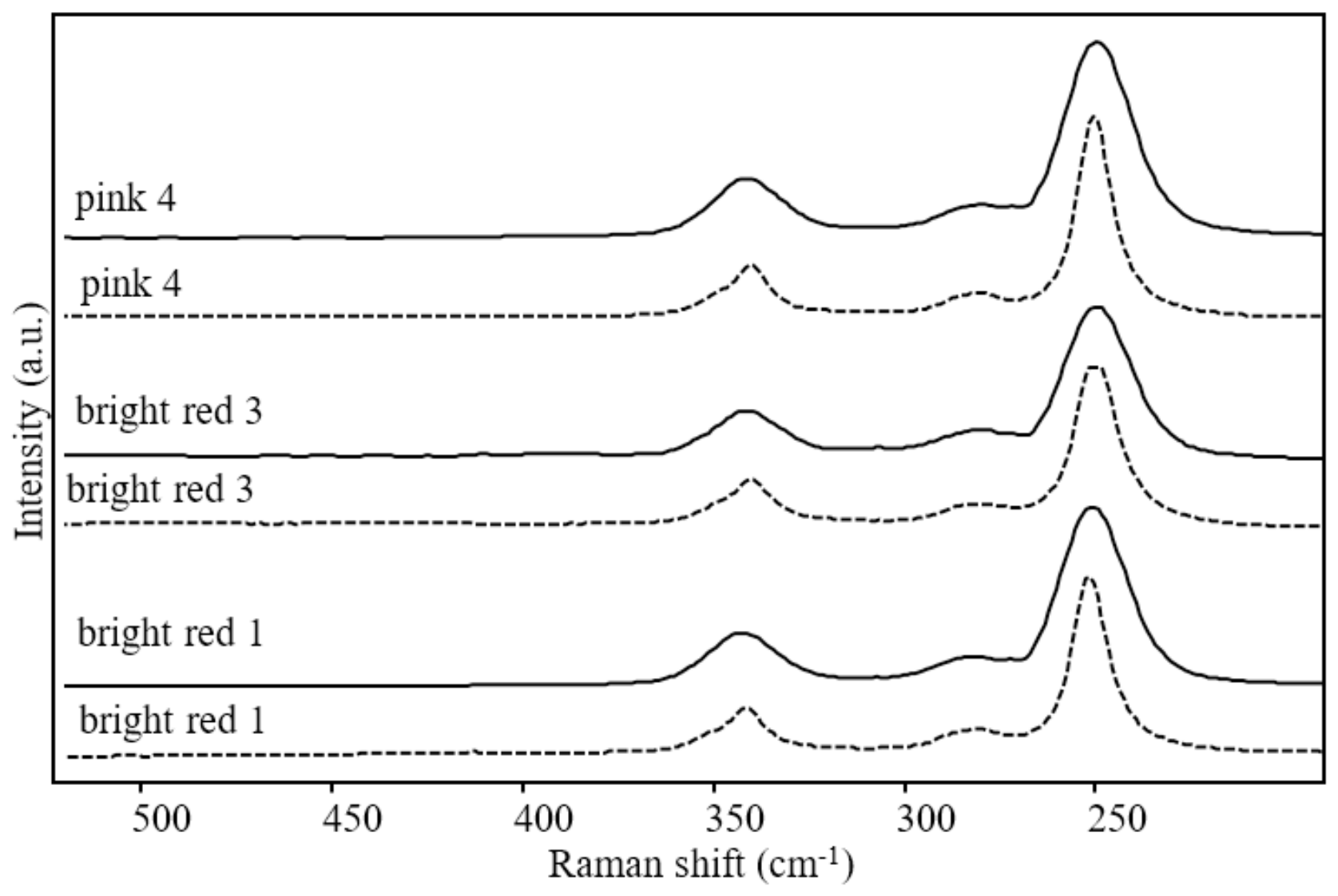

Figure 7

Raman and micro-Raman spectra of cinnabar obtained with $1064 \mathrm{~nm}$ excitation (solid line) and $785 \mathrm{~nm}$ excitation (dotted line) on bright red and pink samples 


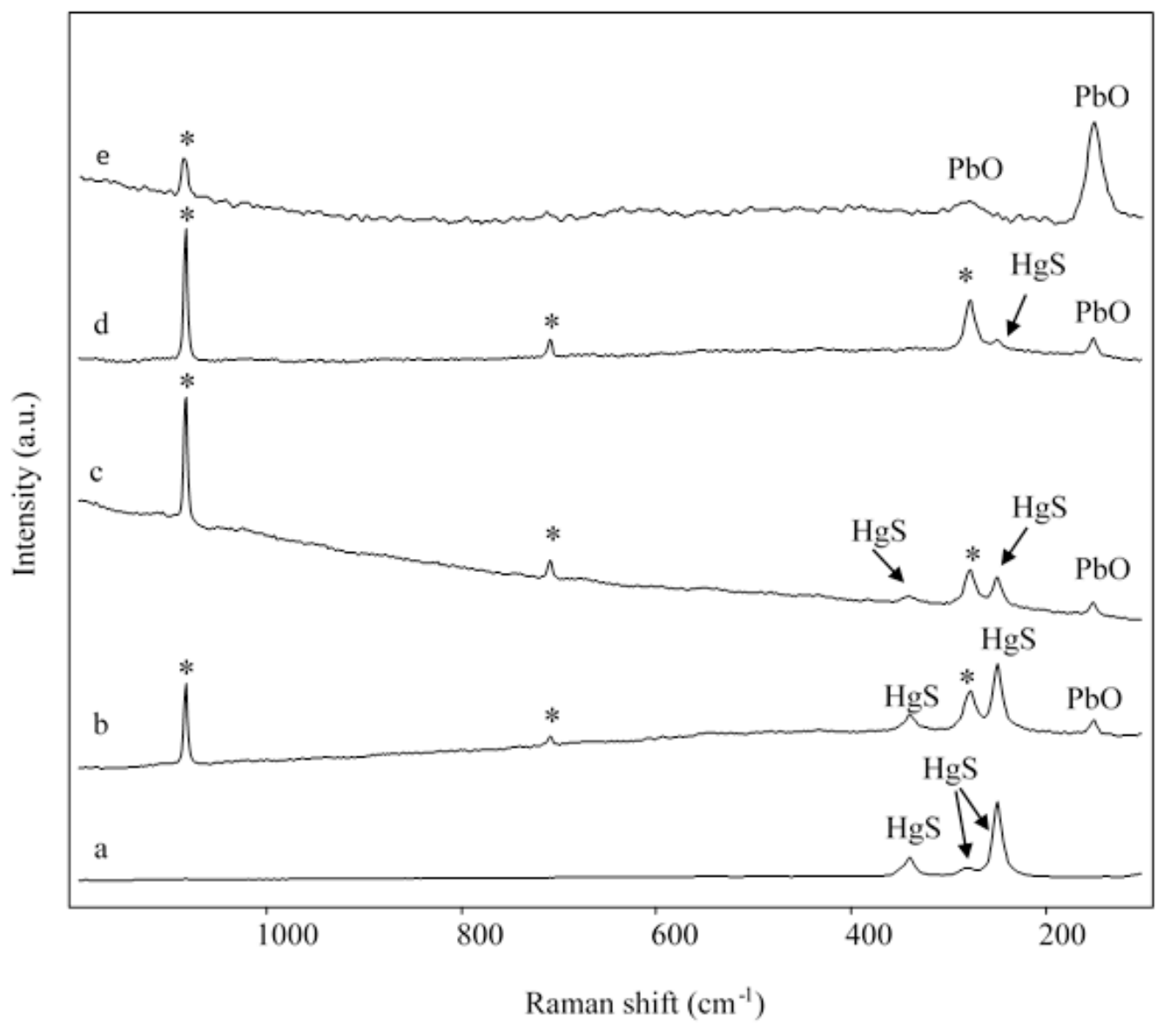

Figure 8

Micro-Raman spectra $(\lambda$ exc=785 nm) acquired on different grains on the surface of pink sample 4. From bottom to top: a) cinnabar; b), c), d) cinnabar, calcite (peaks marked with an asterisk) and litharge in different proportions; e) litharge and calcite 


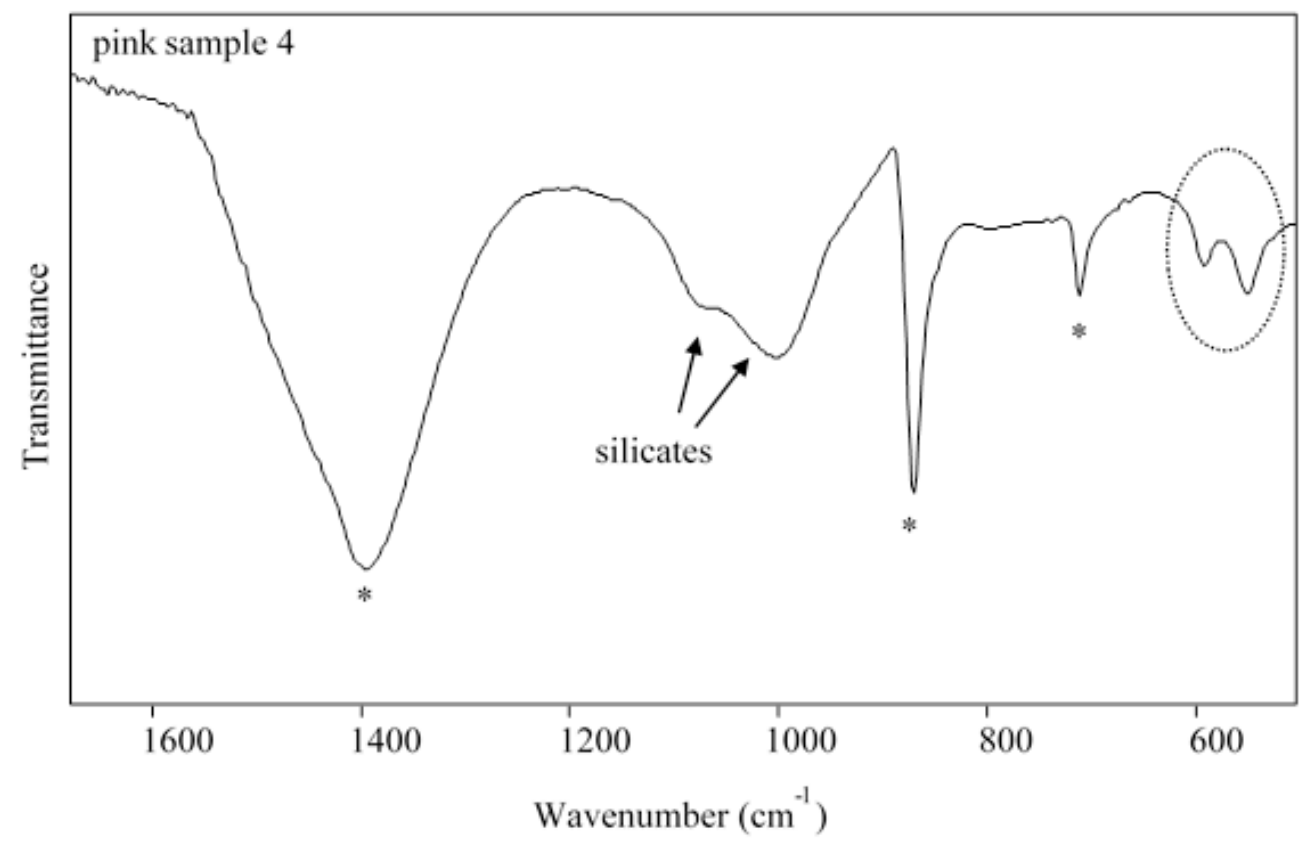

\section{Figure 9}

ATR-FTIR spectrum obtained for pink sample. Bands of calcium phosphate are highlighted by the ellipsis; asterisks indicate calcite
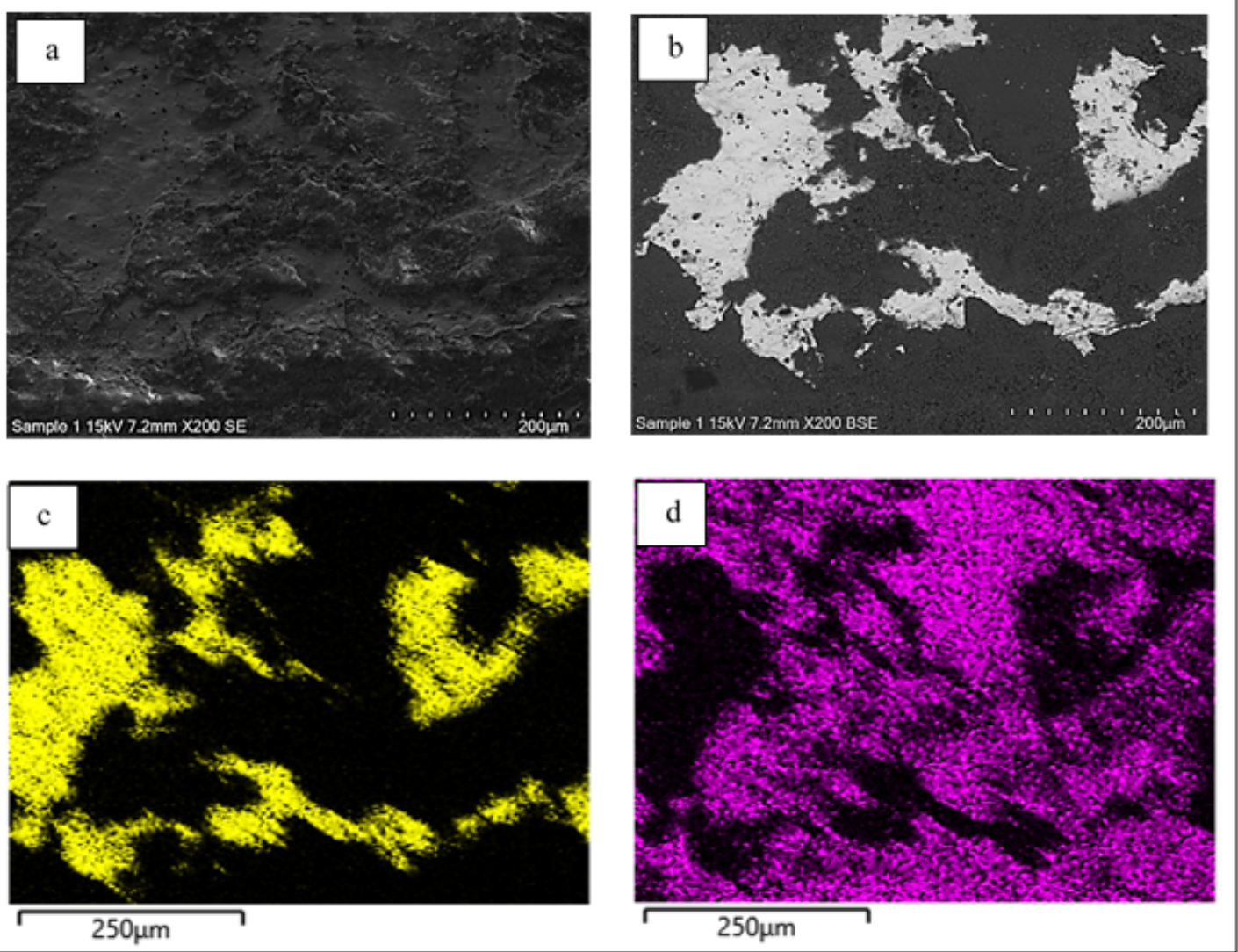
Figure 10

SEM-EDX analysis on an area of about $650 \times 500 \mu \mathrm{m} 2$ of the gilded surface of sample 1: a) SE image; b) BSE image; c) and $\mathrm{d}$ ) distribution of respectively gold ( $\mathrm{M}$ series) and calcium ( $\mathrm{K}$ series)

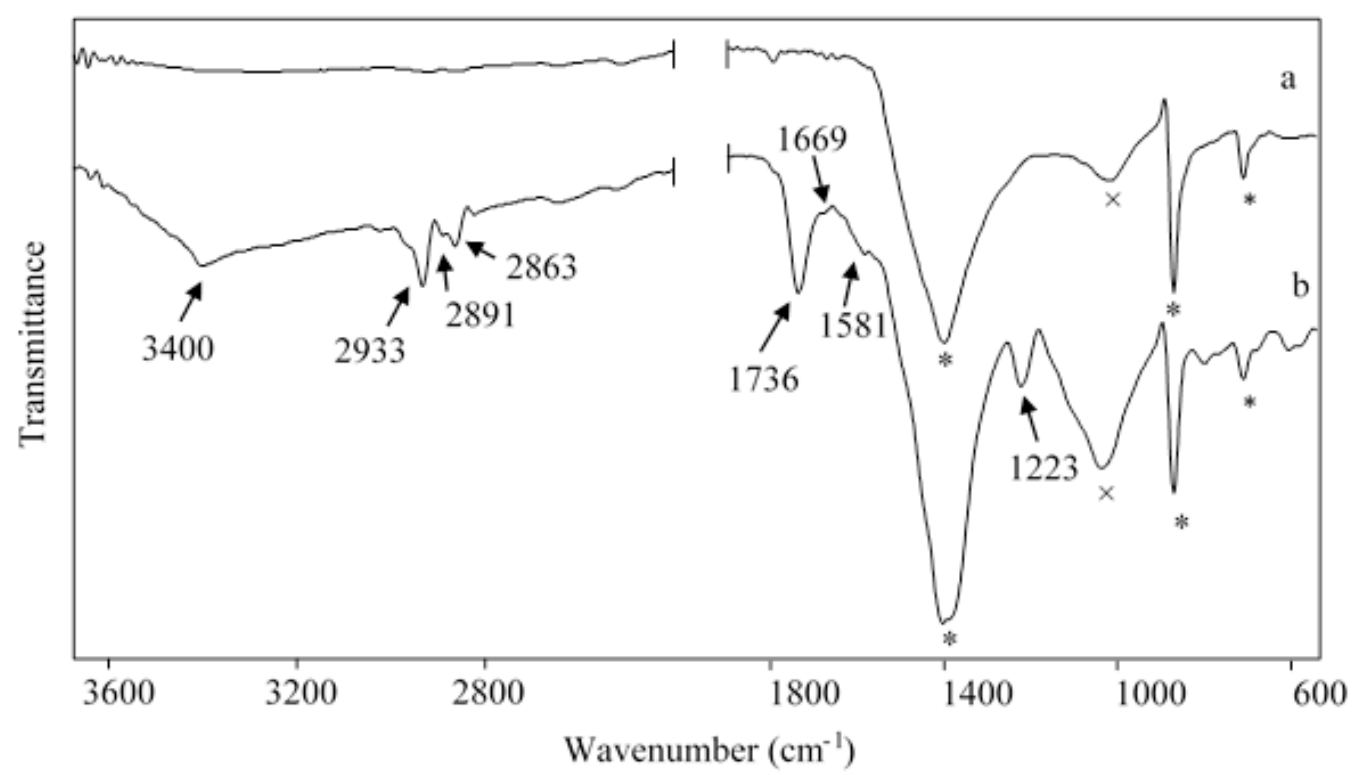

Figure 11

ATR-FTIR spectra of a) micro-sample collected from the red surface of fragment 1 and b) micro-sample collected from the gilded surface of the same fragment. The bands of the organic binder are indicated by arrows; calcite $(*)$ and silicates $(x)$ bands are also pointed out 

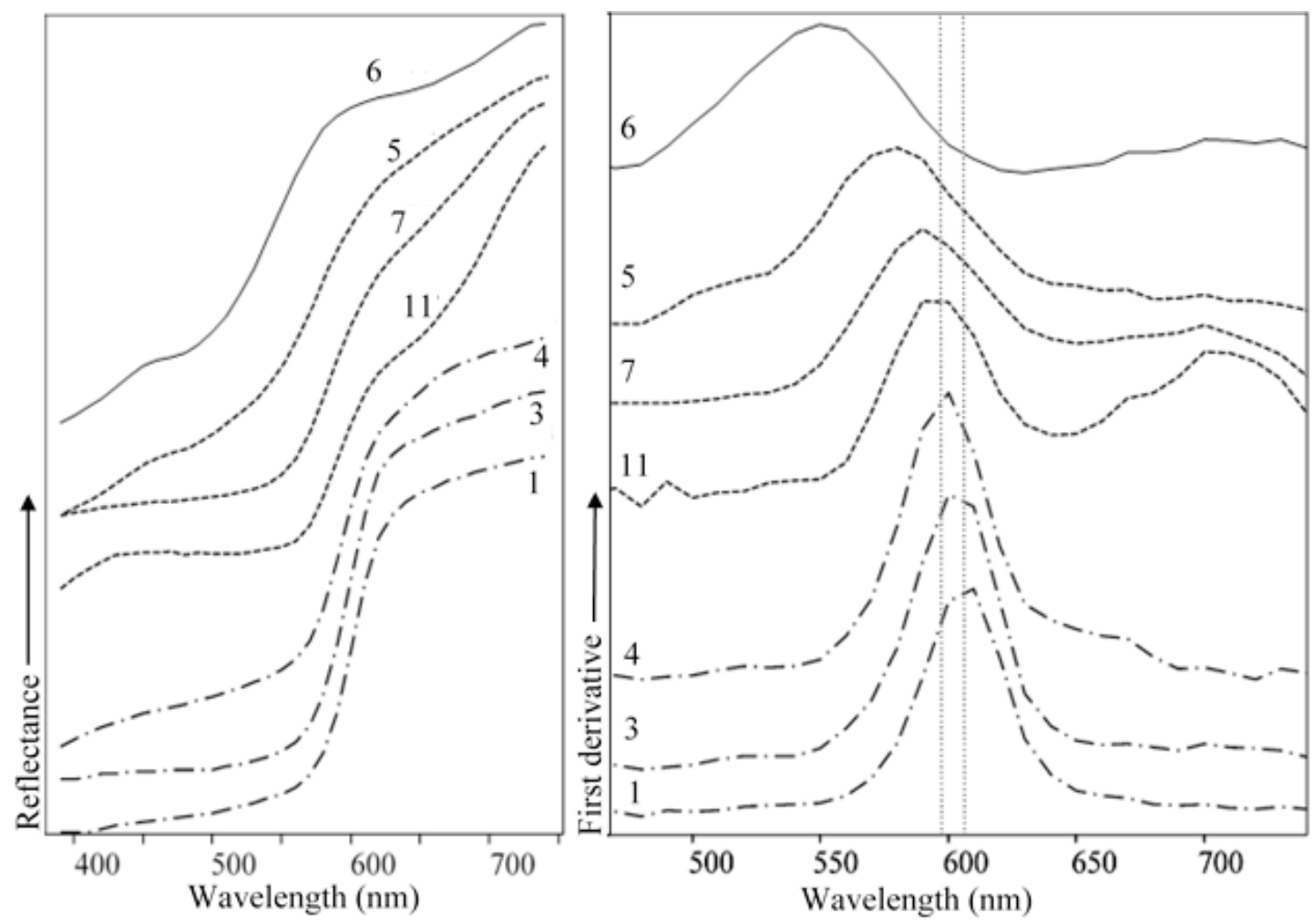

Figure 12

On the left, visible reflectance spectra of bright red (1 and 3), pink (4), violet (11), red (7), light red (5) and yellow (6) samples; on the right their first derivative. The vertical dotted grey lines indicate the position of maxima of first derivatives of pink (left) and bright red (right) 